\title{
Systematic study of the impact of fresh water fluxes on the glacial carbon cycle
}

\author{
N. Bouttes ${ }^{1,2}$, D. M. Roche ${ }^{1,3}$, and D. Paillard ${ }^{1}$ \\ ${ }^{1}$ Laboratoire des Sciences du Climat et de l'Environnement, UMR8212, IPSL-CEA-CNRS-UVSQ - Centre d'Etudes \\ de Saclay, Orme des Merisiers bat. 701, 91191 Gif Sur Yvette, France \\ ${ }^{2}$ NCAS-Climate, Meteorology Department, University of Reading, Reading, RG66BB, UK \\ ${ }^{3}$ Faculty of Earth and Life Sciences, Section Climate Change and Landscape dynamics, Vrije Universiteit Amsterdam, \\ De Boelelaan, 1085, 1081 HV Amsterdam, The Netherlands
}

Correspondence to: N. Bouttes (n.bouttes@ reading.ac.uk)

Received: 4 April 2011 - Published in Clim. Past Discuss.: 26 April 2011

Revised: 12 February 2012 - Accepted: 13 February 2012 - Published: 20 March 2012

\begin{abstract}
During glacial periods, atmospheric $\mathrm{CO}_{2}$ concentration increases and decreases by around $15 \mathrm{ppm}$. At the same time, the climate changes gradually in Antarctica. Such climate changes can be simulated in models when the AMOC (Atlantic Meridional Oceanic Circulation) is weakened by adding fresh water to the North Atlantic. The impact on the carbon cycle is less straightforward, and previous studies give opposite results. Because the models and the fresh water fluxes were different in these studies, it prevents any direct comparison and hinders finding whether the discrepancies arise from using different models or different fresh water fluxes.

In this study we use the CLIMBER-2 coupled climate carbon model to explore the impact of different fresh water fluxes. In both preindustrial and glacial states, the addition of fresh water and the resulting slow-down of the AMOC lead to an uptake of carbon by the ocean and a release by the terrestrial biosphere. The duration, shape and amplitude of the fresh water flux all have an impact on the change of atmospheric $\mathrm{CO}_{2}$ because they modulate the change of the AMOC. The maximum $\mathrm{CO}_{2}$ change linearly depends on the time integral of the AMOC change. The different duration, amplitude, and shape of the fresh water flux cannot explain the opposite evolution of ocean and vegetation carbon inventory in different models. The different $\mathrm{CO}_{2}$ evolution thus depends on the AMOC response to the addition of fresh water and the resulting climatic change, which are both model dependent. In CLIMBER-2, the rise of $\mathrm{CO}_{2}$ recorded in ice cores during abrupt events can be simulated under glacial conditions, especially when the sinking of brines in
\end{abstract}

the Southern Ocean is taken into account. The addition of fresh water in the Southern Hemisphere leads to a decline of $\mathrm{CO}_{2}$, contrary to the addition of fresh water in the Northern Hemisphere.

\section{Introduction}

During glacial periods, the global climate experiences rapid temperature shifts as recorded by numerous proxies from ice and sediment cores. These changes, called abrupt events (Clement and Peterson, 2008), are characterized by an abrupt warming followed by a cooling in the Northern Hemisphere. In the Southern Hemisphere, Antarctica starts to warm as soon as temperatures drop in Greenland, then Antarctica cools down when Greenland rapidly warms (EPICA community members, 2006; Ahn and Brook, 2008; Barker et al., 2009). During these events, ice core records indicate that atmospheric $\mathrm{CO}_{2}$ rises by around $15 \mathrm{ppm}$ within 2000 to $4000 \mathrm{yr}$, generally synchronously with Antarctic warming, and then decreases more gradually than the Antarctic temperature decline (Ahn and Brook, 2008).

Fresh water flux (FWF) inputs into the Atlantic Ocean have been suggested as a trigger for such abrupt changes. Model simulations show that adding fresh water into the North Atlantic results in a significant Atlantic Meridional Overturning Circulation (AMOC) decrease (Stocker and Wright, 1991; Ganopolski and Rahmstorf, 2001). It leads to a reduction in heat transport from the Southern Hemisphere to the Northern Hemisphere, hence a cooling in the North 
and warming in the South (the "bipolar seesaw", Crowley, 1992; Stocker, 1998). Proxy data (presence of ice rafted debris), indicate that massive iceberg discharges happened simultaneously with some of these events (Heinrich events), which brings support to the hypothesis of fresh water input (Bond et al., 1993; Heinrich, 1988; Ruddiman, 1977). Yet the causes of the iceberg discharges are still debated (AlvarezSolas et al., 2010).

Additionally, model studies have shown that the change of oceanic circulation resulting from fresh water inputs can also impact the carbon cycle. However, studies of the impact of fresh water fluxes on atmospheric $\mathrm{CO}_{2}$, especially during glacial periods, are sparse and their results vary widely. Using an ocean-only model, Marchal et al. (1998) simulated a $\mathrm{CO}_{2}$ increase of 10-30 ppm due to the decrease of ocean solubility (caused by the warming of the Southern Hemisphere) for preindustrial boundary conditions. On the other hand, simulations performed with a terrestrial biosphere model under glacial conditions also give a $\mathrm{CO}_{2}$ rise of approximately $6 \mathrm{ppm}$ and then a decline back to the initial value (Köhler et al., 2005). The fresh water flux in this study is $0.3 \mathrm{~Sv}$ distributed during $1000 \mathrm{yr}$. When both the ocean and terrestrial biosphere are taken into account, the coupling of the three main carbon reservoirs relevant on such time scales of a few thousand years, i.e. the ocean, terrestrial biosphere and atmosphere, has to be considered. Under preindustrial conditions, two Atmosphere-Ocean Global Climate Models (AOGCM) and an intermediate complexity model (EMIC) give a $\mathrm{CO}_{2}$ rise in response to the addition of fresh water in the North Atlantic, mostly due to a reduction of the terrestrial biosphere (Obata, 2007; Bozbiyik et al., 2011; Menviel et al., 2008). Additionally, two intermediate complexity climatebiogeochemical models were also used with glacial boundary conditions. The UVic model results in a $\mathrm{CO}_{2}$ increase of $25 \mathrm{ppm}$ when forced by $0.2 \mathrm{~Sv}$ during $1700 \mathrm{yr}$ (Schmittner and Galbraith, 2008). The higher atmospheric $\mathrm{CO}_{2}$ is due to the loss of carbon from the ocean while the terrestrial biosphere stores more carbon. Another study gives opposite results, with the ocean taking up more carbon and the terrestrial biosphere losing carbon, resulting in a $\mathrm{CO}_{2}$ decrease of around 13 ppm (Menviel et al., 2008) (with the FWF changes represented by a triangular function increasing up to $2 \mathrm{~Sv}$ during $200 \mathrm{yr}$ ). Such different results could arise from the differences in the models themselves, the type of experiments (i.e. the type of fresh water fluxes) or the background climate state considered (e.g. relatively cold/warm climate). For example, two background climate states in Menviel et al. (2008) give different $\mathrm{CO}_{2}$ changes as the response results from a fine balance between changes in the terrestrial and marine carbon reservoirs. For preindustrial conditions the $\mathrm{CO}_{2}$ increases then decreases; for glacial conditions the $\mathrm{CO}_{2}$ first declines then rises. To disentangle these effects, we use a single model and test the impact of different fresh water flux experiments and different climate states.
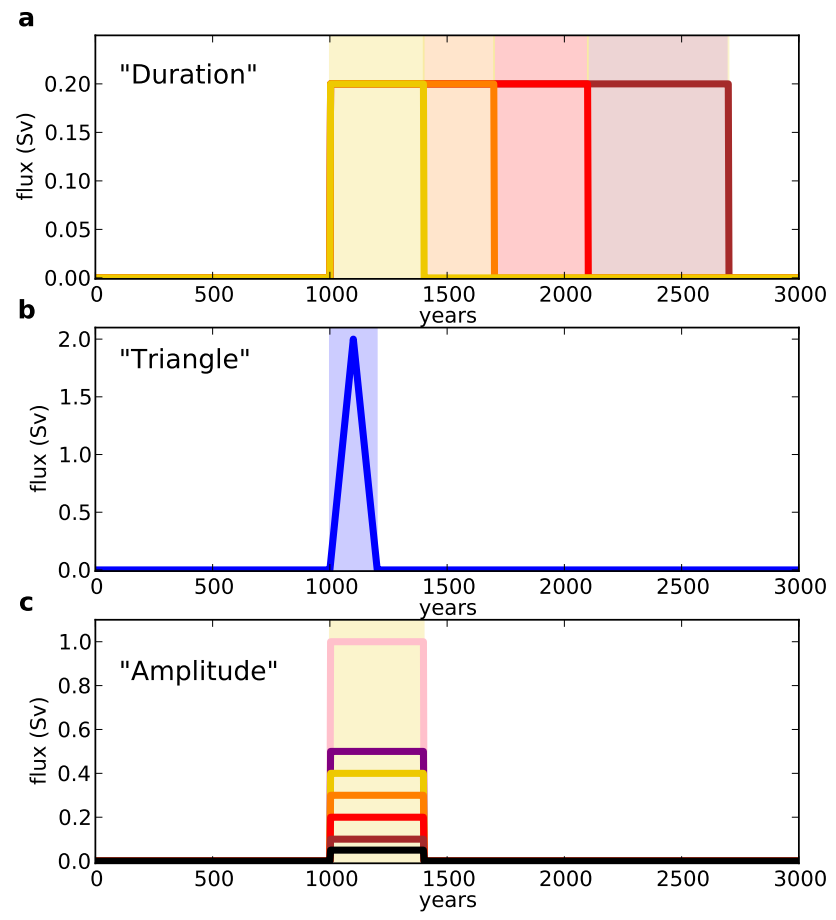

Fig. 1. Evolution of the fresh water flux (Sv) in the three types of experiments: (a) for the "Duration" experiments with fresh water fluxes of $0.2 \mathrm{~Sv}$ added during 400, 700, 1100 or $1700 \mathrm{yr}$, (b) for the "Triangle" experiments with a fresh water flux linearly increasing for $100 \mathrm{yr}$ to $2 \mathrm{~Sv}$, then decreasing again from $100 \mathrm{yr}$, and (c) for the "Amplitude" experiments with fresh water flux added during $400 \mathrm{yr}$ of $0.05,0.1,0.2,0.3,0.4,0.5$ or $1 \mathrm{~Sv}$.

In this study we perform simulations with an intermediate complexity climate-carbon coupled model that includes the ocean and the terrestrial biosphere. We systematically study the impact of different fresh water fluxes by modifying their amplitude, shape and duration, with three different background climate conditions. We first perform similar simulations as Schmittner and Galbraith (2008) and Menviel et al. (2008) by adding fresh water fluxes of different duration and shape to the Northern Atlantic under Preindustrial (PI) and Last Glacial Maximum (LGM, approximately $21000 \mathrm{yr}$ ago) conditions, which allow a direct comparison to their results (Fig. 1a and b). We also run additional simulations with different amplitudes of the fresh water flux to assess its impact (Fig. 1c). We then explore the impact of the same fresh water fluxes in a situation with more realistic glacial $\mathrm{CO}_{2}$ levels obtained including the "brine sinking" mechanism previously studied (Bouttes et al., 2010, 2011). Finally, we evaluate the impact of adding fresh water flux to the Southern Ocean. 


\section{Methods}

\subsection{CLIMBER-2 climate-carbon model}

We use the climate-carbon coupled model CLIMBER-2 (Petoukhov et al., 2000; Ganopolski et al., 2001; Brovkin et al., 2002, 2007). CLIMBER-2 is a model of intermediate complexity fast enough to run numerous long simulations. The simulations are run for $20000 \mathrm{yr}$ to ensure the carbon cycle equilibrium. Running numerous simulations allows us to span various fresh water fluxes (changing the amplitude, shape and duration of the flux), background climates (modern and glacial) and location (Northern or Southern Hemisphere). Hence, we can both compare the results with previous studies and complement with additional ones. CLIMBER-2 includes a statistical atmosphere, a zonally averaged ocean and a terrestrial biosphere model (VECODE) (Brovkin et al., 1997). The model computes the carbon cycle both in the ocean and on land, and takes into account carbonate compensation. It has already been used for a number of studies on the links between the climate and the carbon cycle (Brovkin et al., 2002, 2007; Bouttes et al., 2010, 2011).

\subsection{Sinking of brines in CLIMBER-2}

Brines are small pockets of very salty water released by sea ice formation. Indeed, sea ice consists mainly of fresh water and most of the salt is rejected from the ice during its formation. In the standard version of CLIMBER-2, the flux of salt released to the ocean goes to the surface oceanic cell. The volume of the latter is quite big due to the coarse resolution, and the salt flux is diluted. Yet, as brines are very dense because of their high salt content, they should rapidly sink to the deep ocean when the local conditions allow this. To avoid the dilution of such an effect, the brine sink has been previously parameterized and studied in CLIMBER-2 (Bouttes et al., 2010, 2011). These studies focused on the Southern Ocean where the interactions with the continental shelves are important; hence no sinking of brines is considered in the Northern Hemisphere. The relative importance of the brine mechanism is set by the parameter "frac", which is the fraction of salt released by sea ice formation that sinks to the bottom of the ocean. The rest of the salt $(1-$ frac $)$ is mixed in the corresponding surface oceanic cell as done in the standard version. This mechanism was shown to result in a net glacial $\mathrm{CO}_{2}$ decrease. Previous studies also showed that frac $=0.6$ is a good estimate (Bouttes et al., 2010, 2011). In this study the frac parameter is thus set to 0.6 when the sinking of brines is taken into account.

\subsection{Design of experiments}

We consider three sets of fresh water fluxes (Fig. 1). The first one ("duration") is similar to the Schmittner and Galbraith (2008) experiments in which the duration of the fresh water flux varies between $400 \mathrm{yr}$ and $1700 \mathrm{yr}$ with an ampli- tude of $0.2 \mathrm{~Sv}$ (Fig. 1a), although no negative flux is applied at the end contrary to Schmittner and Galbraith (2008), as it is not required for a restart of the circulation in CLIMBER-2. The second one ("triangle") is similar to the one of Menviel et al. (2008) with a linear fresh water flux increasing from 0 to $2 \mathrm{~Sv}$ in $100 \mathrm{yr}$ then a symmetrical decrease during the following $100 \mathrm{yr}$ (Fig. 1b). Finally we complete these two sets with one with varying amplitude of the fresh water flux between $0.05 \mathrm{~Sv}$ and $1 \mathrm{~Sv}$ for a duration of $400 \mathrm{yr}$ ("amplitude", Fig. 1c). These fresh water fluxes correspond to a "sea level equivalent" of approximately 7 to $30 \mathrm{~m}$ for the "duration" experiments, $18 \mathrm{~m}$ for the "triangle" experiment, and 0.3 to $36 \mathrm{~m}$ for the "amplitude" experiments. A global salt compensation is performed so that the global mean salinity stays the same during the simulations.

These three sets of fresh water fluxes are first applied in the North Atlantic (between $50^{\circ} \mathrm{N}$ and $67.5^{\circ} \mathrm{N}$ ) with three background climate states: the Preindustrial (PI), Last Glacial Maximum (LGM, approximately $21000 \mathrm{yr}$ ago), and Last Glacial Maximum with the sinking of brines (LGM + brines). The LGM climate is obtained by modifying the orbital parameters (Berger, 1978), ice sheets (Peltier, 2004), sea level (Waelbroeck et al., 2002) and atmospheric $\mathrm{CO}_{2}$ (Monnin et al., 2001) for the radiative code. As done in previous studies (Brovkin et al., 2002, 2007; Bouttes et al., 2010, 2011), the radiative $\mathrm{CO}_{2}$ is imposed so as to obtain a glacial climate. $\mathrm{CH}_{4}$ and $\mathrm{N}_{2} \mathrm{O}$ are not explicitly considered in the model, but the $\mathrm{CO}_{2}$ is an "equivalent $\mathrm{CO}_{2}$ " calculated to reproduce the cumulative radiative effect arising from the changes in $\mathrm{CO}_{2}$, $\mathrm{CH}_{4}$ and $\mathrm{N}_{2} \mathrm{O}$ (Brovkin et al., 2007). This fixed radiative $\mathrm{CO}_{2}$ is different from the geochemical $\mathrm{CO}_{2}$, which is computed interactively by the geochemical model and discussed in this study. This allows for a better comparison with previous work and for a simpler analysis of the carbon cycle response to climate. Finally, we also assess the impact of fresh water fluxes in the Southern Ocean (between $60^{\circ} \mathrm{S}$ and $75^{\circ} \mathrm{S}$ ) during glacial climate (LGM and LGM + brines) with the third set of fresh water fluxes (different amplitudes).

\section{Results and discussion}

\subsection{Experiments with preindustrial background climate}

We first perform a set of experiments with fixed preindustrial boundary conditions. Whatever the amplitude or duration of the additional freshwater flux, the AMOC is slowed down as a result of the additional fresh water (Fig. 2a-c). If the amount of fresh water reaches the threshold value of $0.2 \mathrm{~Sv}$, the AMOC is even stopped momentarily, a situation called the "off" mode and previously studied with this model in more detail (Ganopolski et al., 2001). The duration of the "off" mode depends both on the amplitude and duration of 

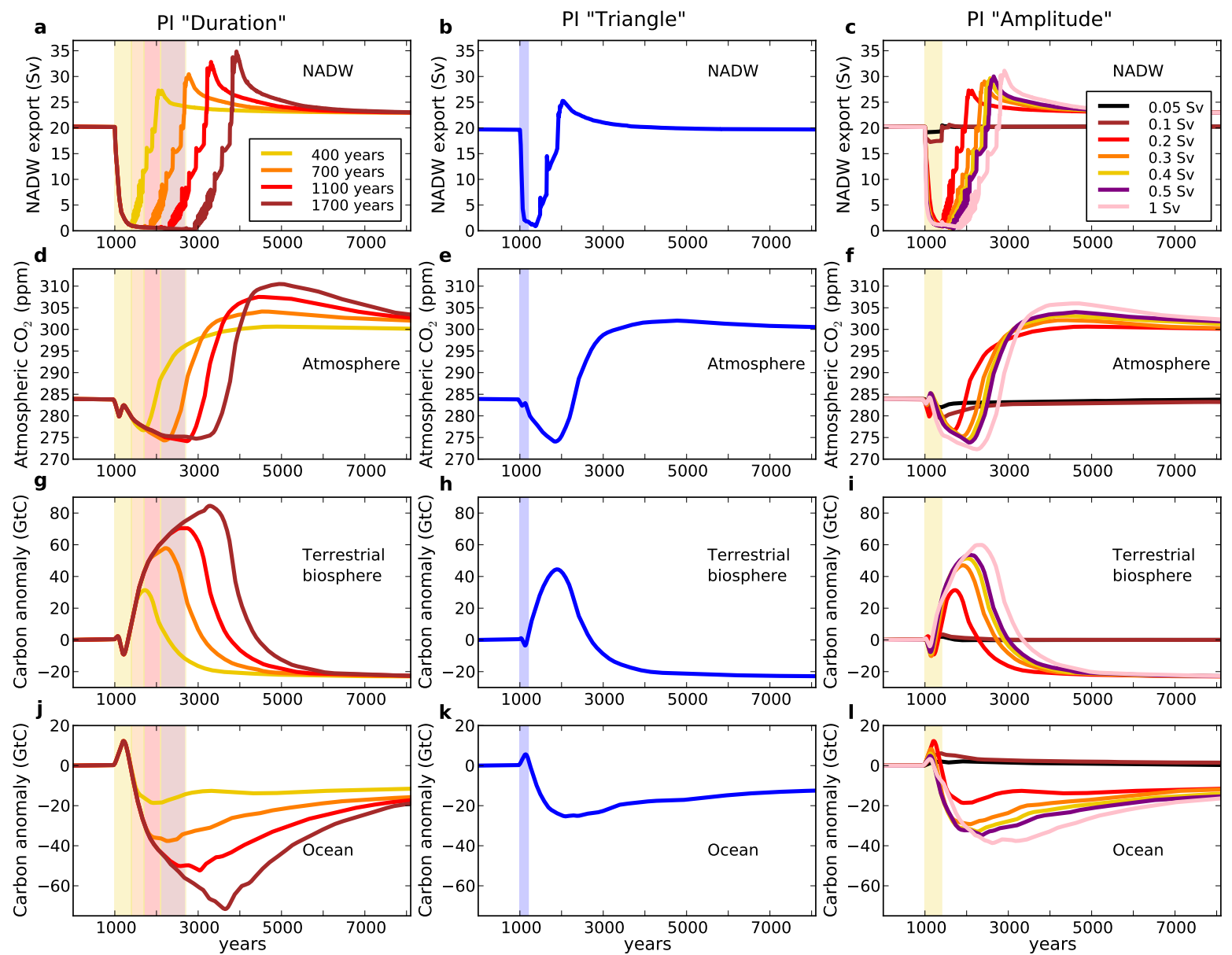

Fig. 2. Evolution of (a, b, c) NADW export (Sv) (maximum of the AMOC), (d, e, f) atmospheric $\mathrm{CO}_{2}$ (ppm), (g, h, i) carbon content anomaly in the terrestrial biosphere $(\mathrm{GtC})$ and $(\mathbf{j}, \mathbf{k}, \mathbf{l})$ carbon content anomaly in the ocean $(\mathrm{GtC})$ during the simulations with the Preindustrial (PI) background climate state. The fresh water flux is added into the North Atlantic and varies as described in Fig. 1 for the three types of experiments: (a, d, g, i) "Duration", (b, e, h, k) "Triangle" and $(\mathbf{c}, \mathbf{f}, \mathbf{i}, \mathbf{l})$ "Amplitude".

the fresh water input: the longer and the bigger the flux, the longer the "off" mode lasts.

In agreement with past studies with CLIMBER-2 (Ganopolski et al., 2001), the alteration of the oceanic circulation leads to warming in the Southern Hemisphere and cooling in the Northern Hemisphere, with greater amplitude at high latitudes (Fig. 3a and c). The precipitation field is also modified, albeit with a more complex pattern (Fig. 3b and d). Precipitation generally decreases north of $40^{\circ} \mathrm{N}$. It tends to slightly increase between $15^{\circ} \mathrm{N}$ and $40^{\circ} \mathrm{N}$. Closer to the equator, a dipole forms with less precipitation around the equator and more around $25^{\circ} \mathrm{S}$, which was linked to a southward shift of the ITCZ (Menviel et al., 2008; Bozbiyik et al., 2011). Closer to the equator, a dipole forms with less precipitation around the equator and more around $25^{\circ} \mathrm{S}$, which was linked to a southward shift of the ITCZ. However, contrary to Menviel et al. (2008) and Bozbiyik et al. (2011), wetter conditions are obtained in North Africa.
These changes impact the carbon cycle. When the fresh water flux is too small to stop the AMOC (below the threshold value of $0.2 \mathrm{~Sv}$ the AMOC does not switch to the "off" mode), the resulting change of $\mathrm{CO}_{2}$ is small (less than $5 \mathrm{ppm}$, Fig. $2 \mathrm{c}$ and $\mathrm{f}$ ). Above the $0.2 \dot{\mathrm{S} v}$ threshold, when the AMOC shuts down, the impact of the change of oceanic circulation on the carbon cycle is larger. The atmospheric $\mathrm{CO}_{2}$ first declines for at least $1000 \mathrm{yr}$ and longer if the "off" mode still persists after $1000 \mathrm{yr}$ (with a maximum amplitude of around $10 \mathrm{ppm}$ ). It then starts increasing (with a maximum amplitude of around $25 \mathrm{ppm}$ ) after the AMOC has started increasing again, and reaches a new equilibrium with higher $\mathrm{CO}_{2}$ value (around $300 \mathrm{ppm}$ ) as the AMOC also stabilizes at a higher level (around $24 \mathrm{~Sv}$ compared to $20 \mathrm{~Sv}$ initially). The existence of multiple equilibriums is a classical feature of some climate models (Rahmstorf, 1995) and corresponds here to a small shift in the location of convection in the North Atlantic. As we focus our study on the carbon exchanges during the first transitory phase of the simulations, 

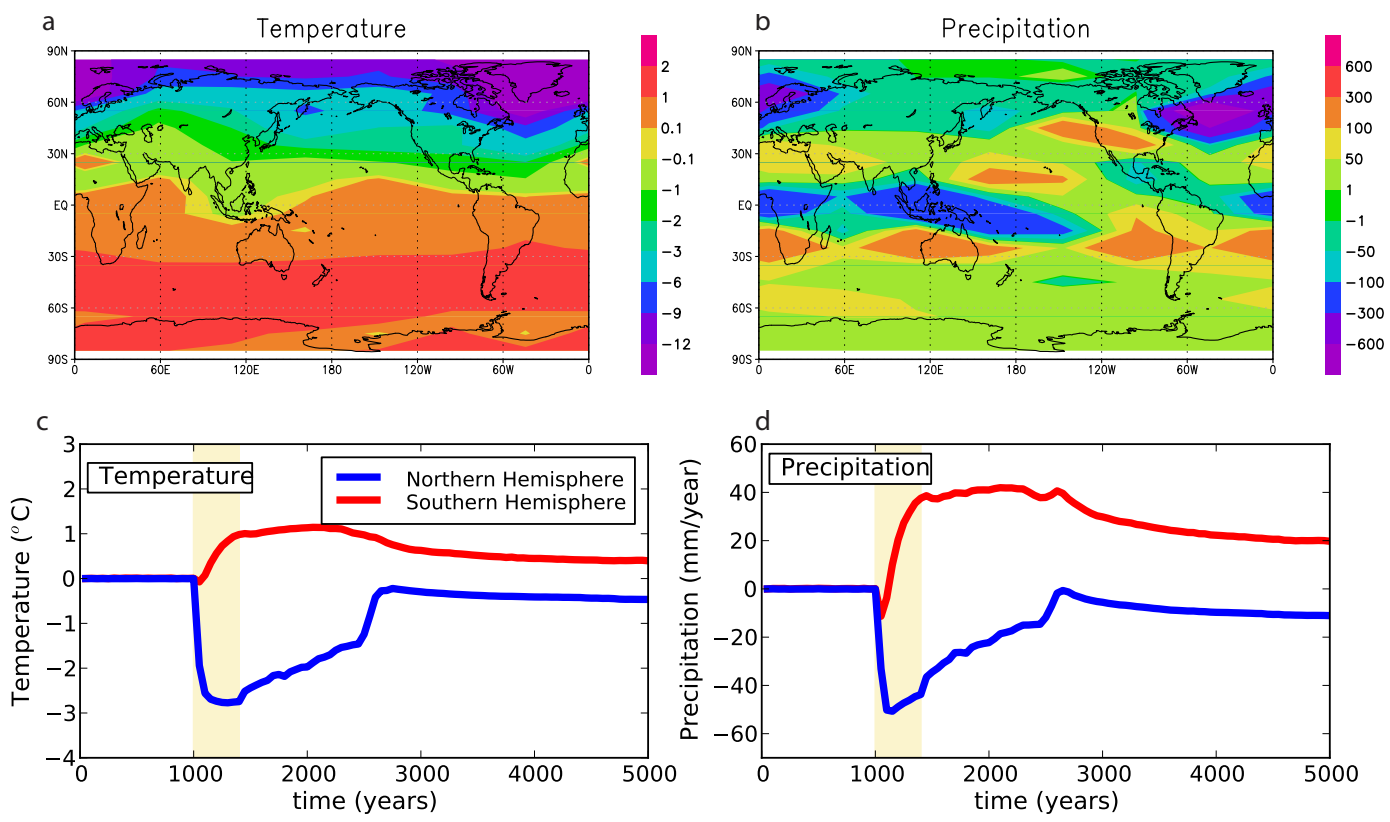

Fig. 3. Temperature and precipitation change. (a) Air temperature $\left({ }^{\circ} \mathrm{C}\right)$ and $(\mathbf{b})$ precipitation $\left(\mathrm{mm} \mathrm{yr}^{-1}\right)$ anomalies for the simulation during the Preindustrial with a fresh water flux added in the North Atlantic of $0.5 \mathrm{~Sv}$ during $400 \mathrm{yr}$. The anomalies refer to the difference between the collapse state of the AMOC compared to the control state (years 1390-1400 minus years 990-1000). (c) and (d) Evolution of (a) air temperature $\left({ }^{\circ} \mathrm{C}\right)$ and $(\mathbf{b})$ precipitation $\left(\mathrm{mm} \mathrm{yr}^{-1}\right)$ in the Northern (blue) and Southern (red) Hemispheres.

i.e. before the return towards the final equilibrium state, this final equilibrium state is not relevant to our discussion here.

The impact of fresh water fluxes and the resulting weakening of the AMOC on the carbon cycle during the Preindustrial has previously been studied with coupled atmosphereocean-vegetation carbon-climate models (Menviel et al., 2008; Obata, 2007; Bozbiyik et al., 2011). In these studies, the terrestrial biosphere becomes a source of carbon and the ocean a sink. This results in an increase of atmospheric $\mathrm{CO}_{2}$. In particular, the LOVECLIM model, which is also used under glacial conditions, results in an atmospheric $\mathrm{CO}_{2}$ rise of around $20 \mathrm{ppm}$ in approximately $100 \mathrm{yr}$ followed by a more gradual decrease of approximately $25 \mathrm{ppm}$ in $400 \mathrm{yr}$ when forced by a fresh water flux as in the "triangle" experiment. The results obtained with CLIMBER-2 are very different. In the similar experiment, CLIMBER-2 simulates a $10 \mathrm{ppm}$ reduction in approximately $1000 \mathrm{yr}$, then an increase of around $25 \mathrm{ppm}$ in $1000 \mathrm{yr}$ (Fig. 2e). Both the duration and sign of the response are thus different.

These differences originate from the different evolutions of the oceanic and terrestrial biosphere carbon reservoirs. In Menviel et al. (2008), the ocean takes up carbon and the terrestrial biosphere releases carbon as soon as the AMOC slows down due to the addition of fresh water flux. Then, in a second phase, the opposite occurs. Because the vegetation reacts faster than the ocean, the $\mathrm{CO}_{2}$ evolution is primarily driven by the vegetation. The ocean tends to mitigate the changes. On the contrary, in CLIMBER-2, the terrestrial biosphere takes up carbon while the ocean looses car- bon (Fig. $2 \mathrm{~h}$ and $\mathrm{k}$ ). Because the amplitude of the change in the terrestrial biosphere is twice as large as in the ocean, it dominates the $\mathrm{CO}_{2}$ evolution and the uptake of carbon by the vegetation resulting in the $\mathrm{CO}_{2}$ decrease. Contrary to LOVECLIM, in all CLIMBER-2 simulations, the ocean looses carbon while the terrestrial biosphere takes it up (Fig. 2). In the following we will discuss why the ocean looses carbon and the terrestrial biosphere takes up carbon.

In the ocean, the salinity decreases in the surface North Atlantic (Fig. 4a) and the formation of deep water in the North Atlantic shuts down (Fig. 5) because of the addition of fresh water. The potential density becomes relatively higher in the Southern Hemisphere compared to adjacent waters (Fig. 4gi). It gives rise to the formation of intermediate water in the three basins around $50^{\circ} \mathrm{S}$ (Fig. 5). Because of the warming in the Southern Hemisphere, warm water is advected deeper so that heat penetrates in the upper part of the ocean (above $-2000 \mathrm{~m}$, Fig. $4 \mathrm{~d}-\mathrm{f}$ ). Due to the lowering of the solubility of $\mathrm{CO}_{2}$ in warmer water, this upper part of the ocean (which excludes smaller areas in the northern part of the Atlantic and Pacific) contains less DIC (Dissolved Inorganic Carbon, Fig. 6a-c). In the deep ocean (below $-2000 \mathrm{~m}$ ) and in the northern parts of the Atlantic and Pacific, there is more DIC as the exchange with the surface has diminished. Moreover, the surface ocean in the Northern Hemisphere is cooler and thus more carbon can be dissolved in the surface water. The greatest change in the organic carbon happens in the northern part of the Northern Hemisphere (not shown). Because the sea ice covers a greater area, the light availability diminishes 

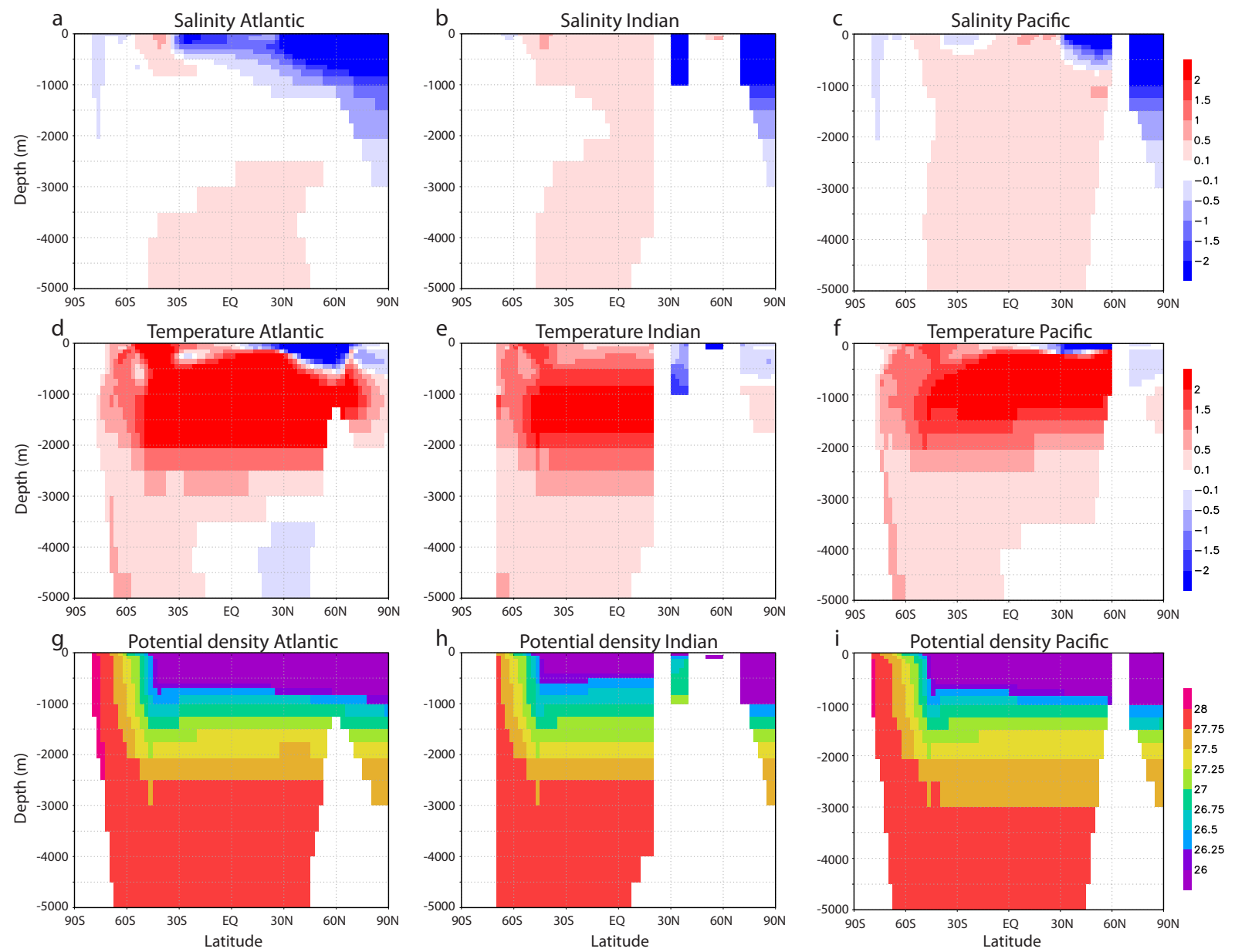

Fig. 4. Zonally averaged salinity (permil) and temperature $\left({ }^{\circ} \mathrm{C}\right)$ anomalies, and density $\left(\mathrm{kg} \mathrm{m}^{-3}\right)$ for the simulation during the Preindustrial with a fresh water flux added in the North Atlantic of $0.5 \mathrm{~Sv}$ during $400 \mathrm{yr}$ : (a, b, c) salinity; (d, e, f) temperature; (g, h, i) density. The anomalies of temperature and salinity refer to the difference between the collapse state of the AMOC compared to the control state (years 1390-1400 minus years 990-1000). The density is taken at the years 1390-1400. The three basins are: (a, d, g) Atlantic, (b, e, h) Indian and (c, f, i) Pacific.

and so does the production of organic carbon. But this effect is small compared to the change of inorganic carbon. Overall, the loss of carbon from most of the upper ocean (especially in the South) dominates, leading to a net loss of carbon from the ocean. The distribution of the alkalinity change is similar to the inorganic carbon change, but with lower amplitude. The change of alkalinity has an opposite effect on $\mathrm{CO}_{2}$ compared to DIC. Because the amplitude of the alkalinity change is smaller than the DIC change, the latter prevails.

The terrestrial biosphere reacts both to the air temperature and precipitation changes. The main changes take place at low latitudes (Fig. 7), contrary to Köhler et al. (2005), but as in Bozbiyik et al. (2011) and Menviel et al. (2008). However the changes of vegetation are different in CLIMBER2. In Africa there is a decrease of carbon by a few GtC in the vegetation around the equator, but an increase of carbon in the vegetation north of $10^{\circ} \mathrm{N}$ and south of $10^{\circ} \mathrm{S}$. In Bozbiyik et al. (2011) the increase of carbon takes place be- tween the equator and $20^{\circ} \mathrm{S}$. In Menviel et al. (2008) the change of carbon content is more similar to CLIMBER-2 around the equator with a reduced carbon content in the vegetation, but this decline also takes place in the Northern part of Africa contrary to CLIMBER-2. In South America there is a loss of carbon by the vegetation in CLIMBER-2 between $10^{\circ} \mathrm{S}$ and $30^{\circ} \mathrm{S}$ but an uptake of carbon everywhere else. In Bozbiyik et al. (2011) there is an increase of carbon between the equator and $20^{\circ} \mathrm{S}$ on the western side of South America. In Bozbiyik et al. (2011) and Menviel et al. (2008), the stock of carbon in the North is reduced contrary to CLIMBER-2. Such disparities between the models can be partly explained by the differences in the precipitation fields. Because CLIMBER-2 is a low resolution model with simplified physics, the distribution of precipitation associated to the weakening of the AMOC is not perfectly represented. Given the differences in the treatment of physics in CLIMBER-2 and LOVECLIM, the computed precipitation fields are not 

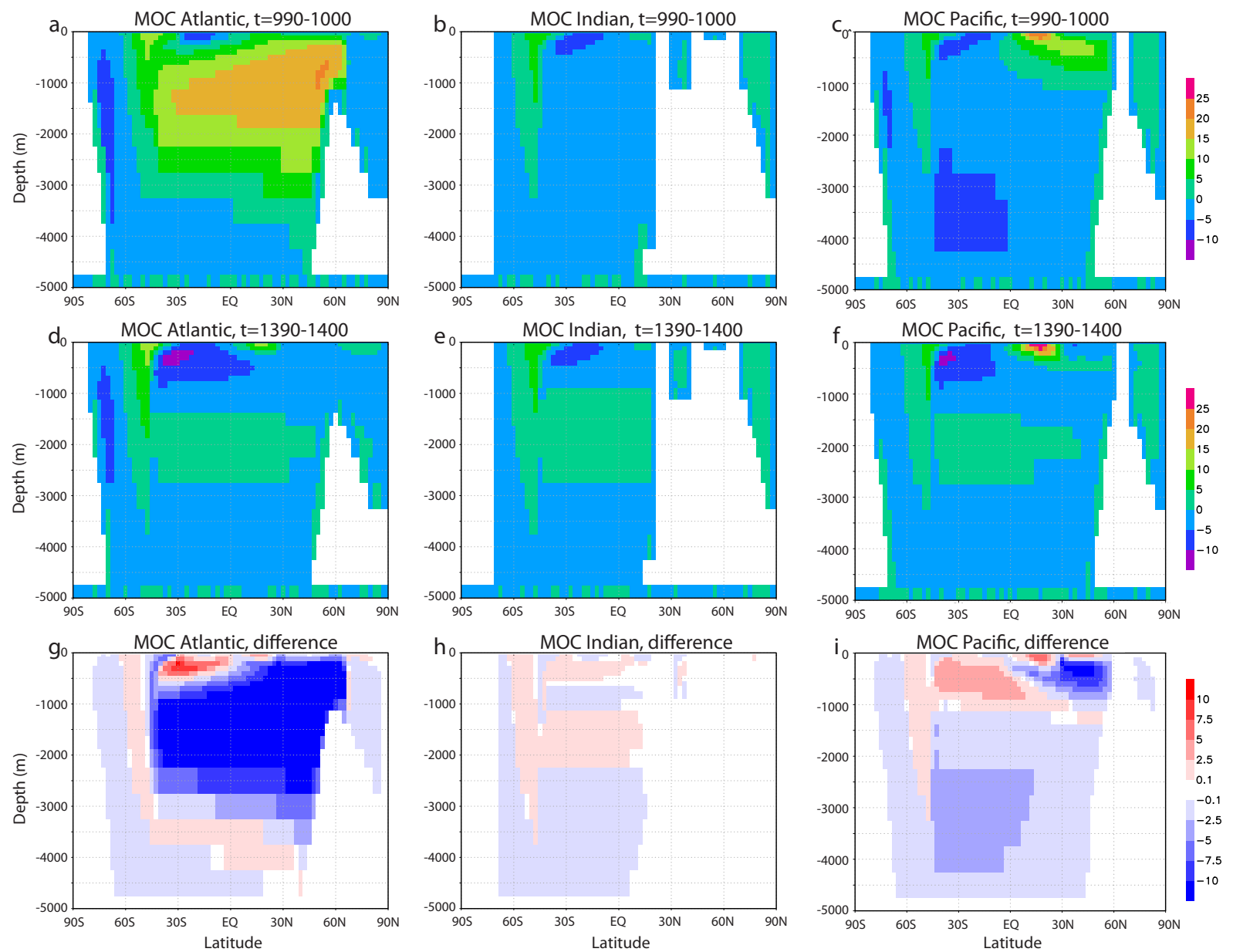

Fig. 5. Meridional overturning streamfunction (Sv) for the simulation during the Preindustrial with a fresh water flux added into the North Atlantic of $0.5 \mathrm{~Sv}$ during $400 \mathrm{yr}$ at $(\mathbf{a}, \mathbf{b}, \mathbf{c})$ the average of years 990-1000, (d, e, f) the average of years 1390-1400 and (g, h, i) the difference between the two for the three basins: $(\mathbf{a}, \mathbf{d}, \mathbf{g})$ Atlantic, $(\mathbf{b}, \mathbf{e}, \mathbf{h})$ Indian and $(\mathbf{c}, \mathbf{f}, \mathbf{i})$ Pacific.

similar. The cause is unclear as CLIMBER-2 has a lower spatial resolution but a higher vertical resolution when compared to LOVECLIM. Since the change of precipitation is an important parameter governing the evolution of the terrestrial biosphere, it leads to different vegetation distributions. Overall, the amount of carbon in the vegetation becomes smaller in the colder and dryer North and larger in the warmer and globally wetter South (Fig. 8). However, the carbon content in the soil increases in both hemispheres. In the North the colder and dryer climate leads to less decomposition. In the South, because the vegetation grows more, the stock of carbon in the soils also becomes larger. Overall, these changes lead to an augmentation of carbon in the terrestrial biosphere. Hence the carbon content increase is mostly driven by the soil carbon changes from the climate response.

Why is the carbon-cycle response different in LOVECLIM? First, we note that the fresh water flux is similar and cannot be the cause of this discrepancy. Moreover, the terrestrial biosphere model (VECODE) is the same in both models, although the resolution is coarser in CLIMBER-2. However, the response of the AMOC is different although the fresh water flux is the same for both models: the AMOC increases as soon as the fresh water flux stops in LOVECLIM (i.e. after $200 \mathrm{yr}$ ) and recovers quickly in approximately $400 \mathrm{yr}$, i.e. $600 \mathrm{yr}$ after the beginning of the fresh water flux. In CLIMBER-2 it takes more time for the AMOC to recover, it reaches its new stable level around $800 \mathrm{yr}$ after the stop of the fresh water flux, i.e. $1000 \mathrm{yr}$ after the beginning of the fresh water flux. The timing of the change of oceanic circulation and climate is thus different, i.e. the changes take more time in CLIMBER-2 compared to LOVECLIM. The slower recovery of he AMOC in CLIMBER-2 can lead to a greater role of the subsurface part of the ocean through solubility changes. In both models, the colder waters in the North can take up more carbon while the warmer waters in the South can take less due to the solubility effect. However, when the formation of deep water recovers in the North Atlantic it brings carbon from the surface to 

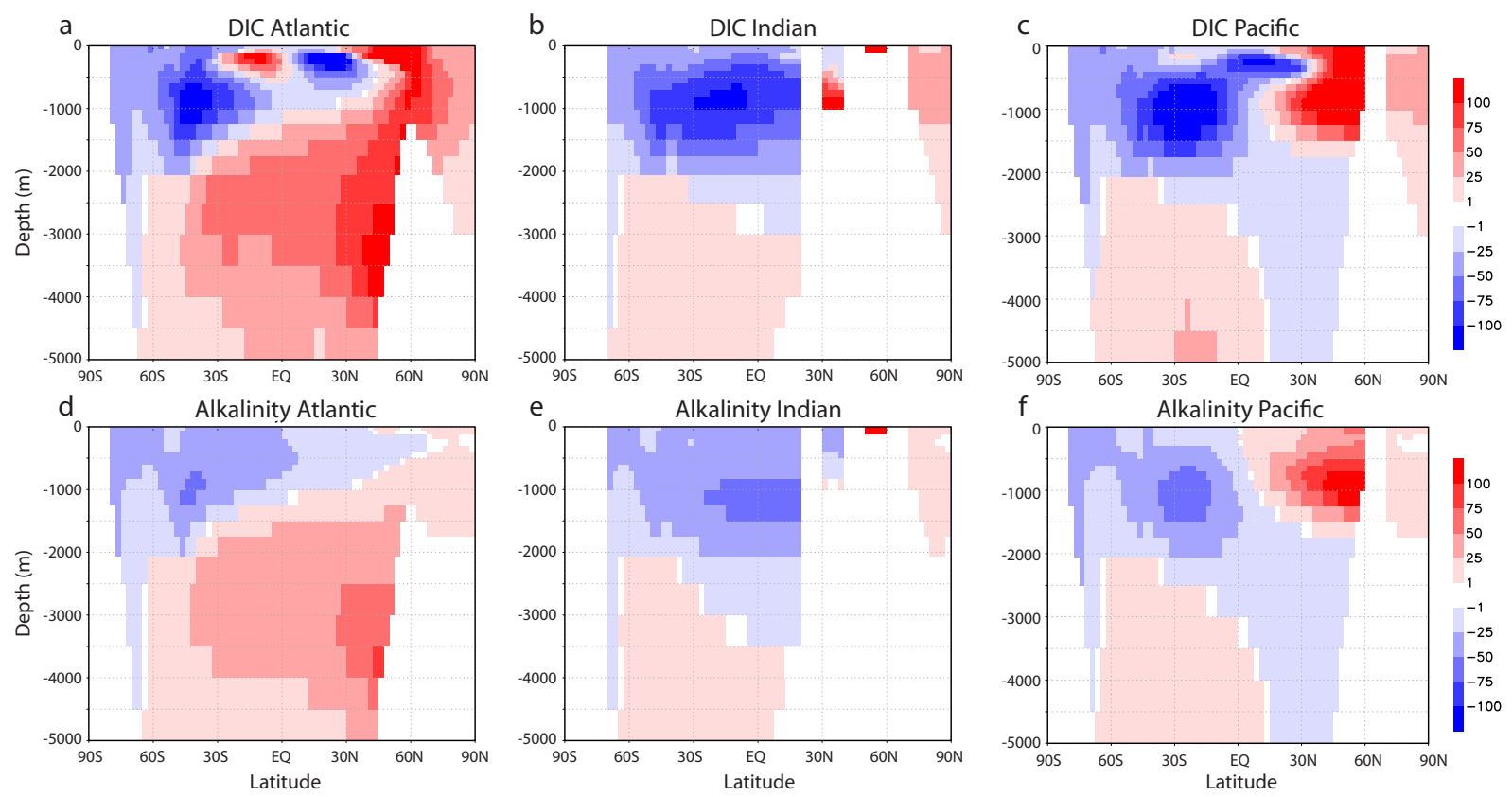

Fig. 6. Zonally averaged dissolved inorganic carbon and alkalinity $\left(\mu \mathrm{mol} \mathrm{kg}{ }^{-1}\right)$ anomalies for the simulation during the Preindustrial with a fresh water flux added into the North Atlantic of $0.5 \mathrm{~Sv}$ during $400 \mathrm{yr}$ : (a, b, c) dissolved inorganic carbon and (d, e, f) alkalinity anomalies. The anomalies refer to the difference between the collapse state of the AMOC compared to the control state (years 1390-1400 minus years 990-1000). The three basins are: (a, d) Atlantic, (b, e) Indian and (c, f) Pacific.
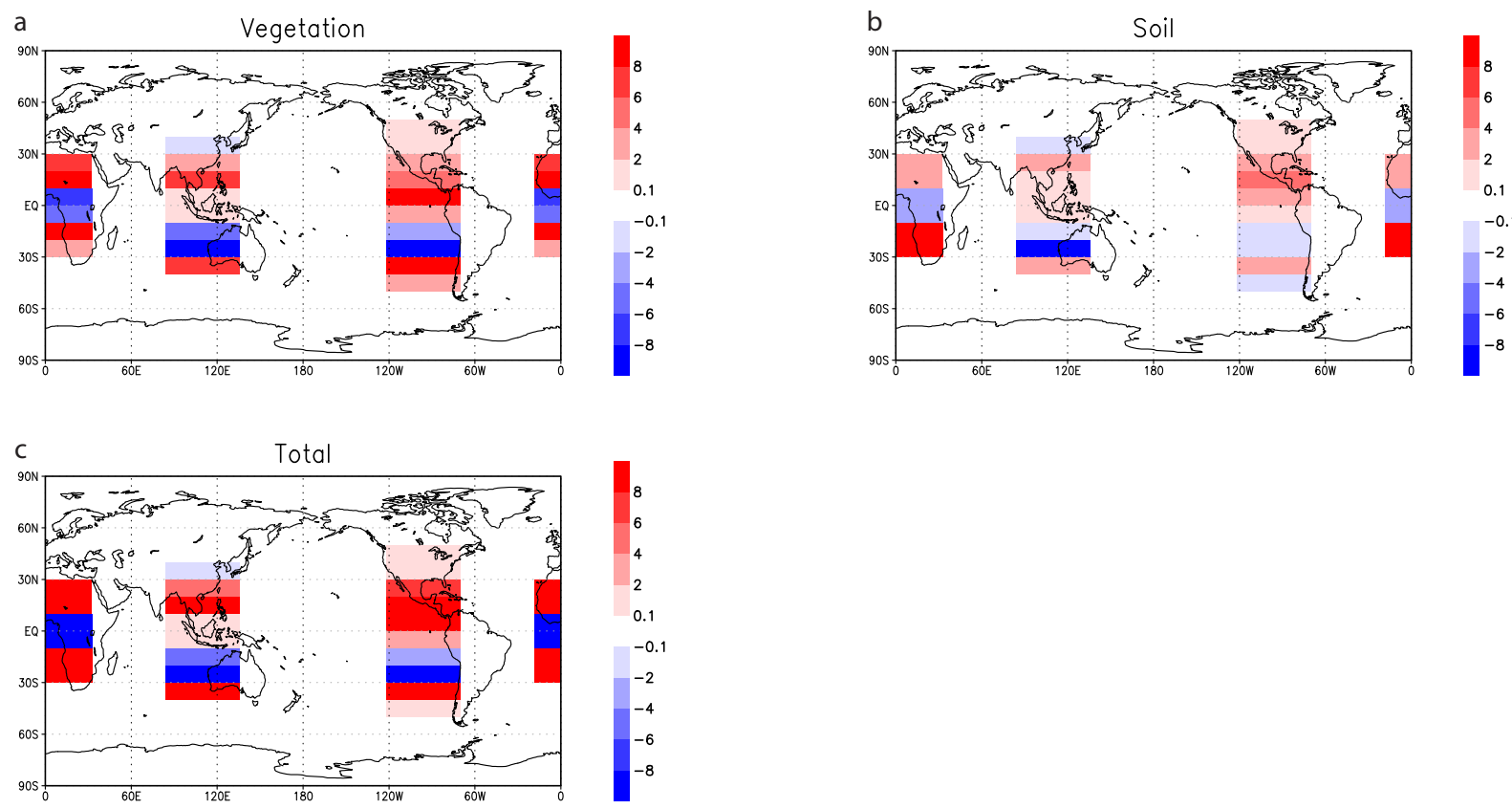

Fig. 7. Change of carbon content (GtC) in (a) the vegetation, (b) soil and (c) total for the simulation during the Preindustrial with a fresh water flux added in the North Atlantic of $0.5 \mathrm{~Sv}$ during $400 \mathrm{yr}$. 

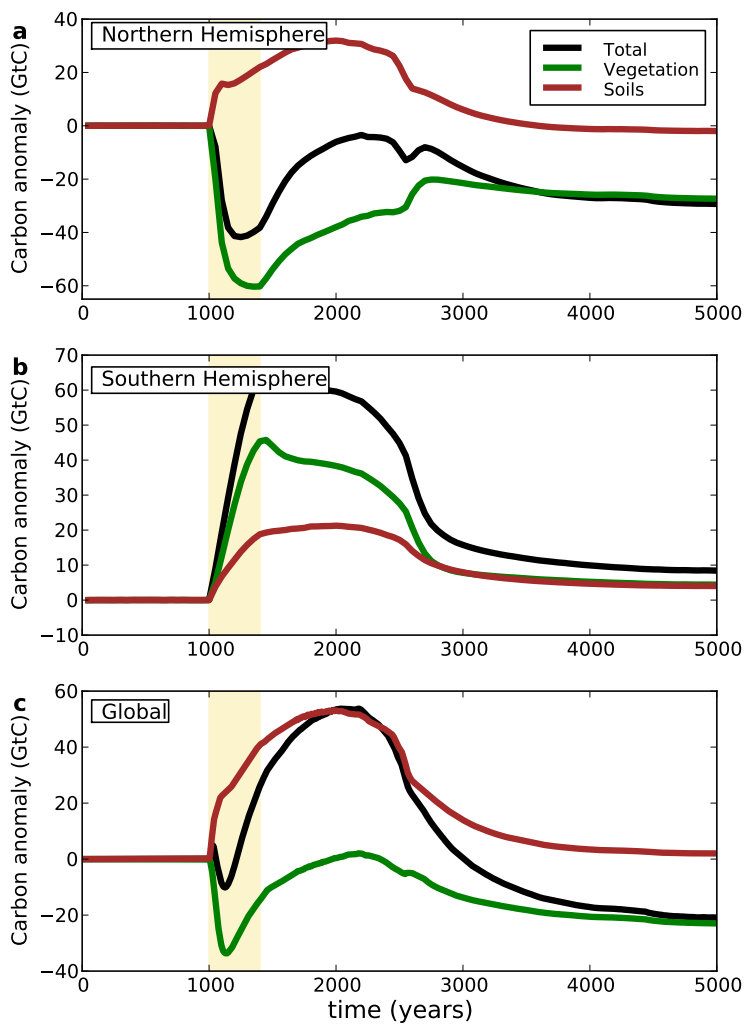

Fig. 8. Evolution of the carbon content anomaly in the terrestrial biosphere (GtC) (a) in the Northern Hemisphere, (b) in the Southern Hemisphere and (c) total of the two hemispheres. The total carbon in the terrestrial biosphere (black) is decomposed in its two subreservoirs: the vegetation (green) and soils (brown). In the simulation the fresh water flux, which is added into the North Atlantic, has an amplitude of $0.5 \mathrm{~Sv}$ during $400 \mathrm{yr}$.

the deep ocean. In CLIMBER-2 this transport of carbon remains stopped longer than in LOVECLIM, so that even though the cold upper ocean can contain more carbon, the latter is not efficiently transported deeper into the ocean. Furthermore, in CLIMBER-2, the formation of intermediate water in the Southern Hemisphere plays an important role when the formation of NADW is stopped. A complete explanation could only be obtained by running additional simulations with LOVECLIM.

Part of the differences can also arise from the simplicity of CLIMBER-2. Indeed, the rapidity of CLIMBER-2 is balanced by some simplifications such as the coarse resolution and zonally averaged ocean. Such simplifications can have different impacts in the context of fresh water flux experiments. First, the gyres and the ACC are prescribed in the model, whereas in reality they could change. It can also introduce a bias in the carbon cycle such as too much remineralisation in intermediate waters. Yet the temperature distribution in the ocean seems to be coherent with other models. The use of a simplified atmospheric model could result in
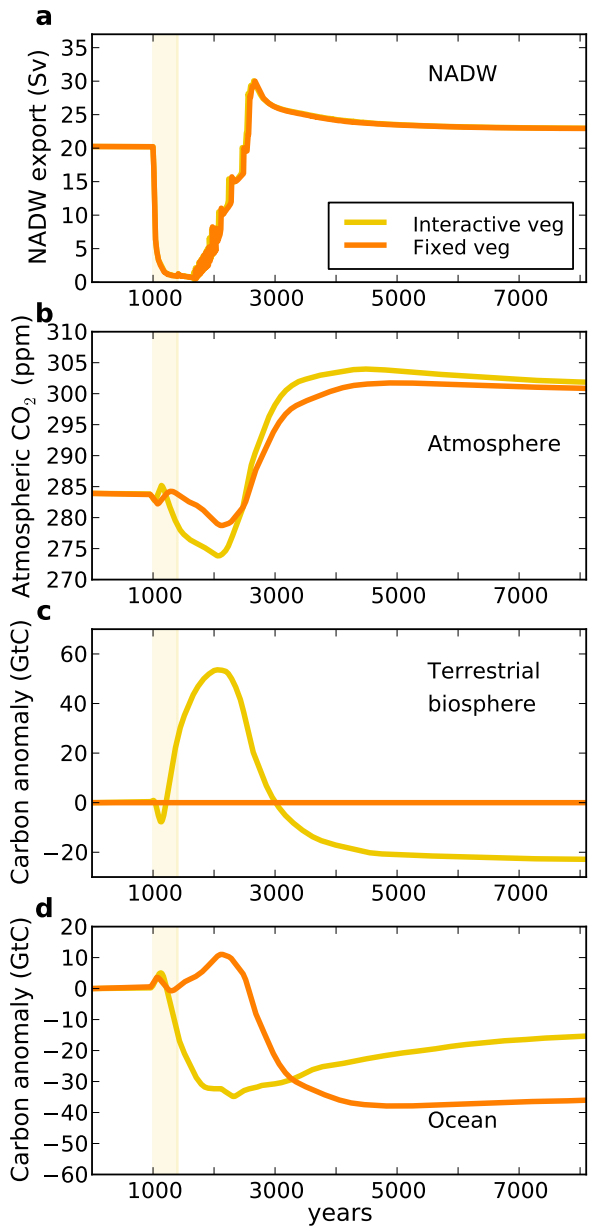

Fig. 9. Evolution of (a) NADW export (Sv) (maximum of the AMOC), (b) atmospheric $\mathrm{CO}_{2}$ (ppm), (c) carbon content anomaly in the terrestrial biosphere (GtC) and (d) carbon content anomaly in the ocean $(\mathrm{GtC})$ during two simulations with the Preindustrial (PI) background climate state. The fresh water flux of $0.5 \mathrm{~Sv}$ for $400 \mathrm{yr}$ is added into the North Atlantic. Yellow line is with interactive vegetation (standard) and orange line with the vegetation fixed to its initial distribution.

less realistic precipitation fields which then impact vegetation. Yet, the pattern of precipitation change is not very different from other models. The terrestrial biosphere is also a simple one with only two types of vegetation: grass and tree, but is also used in LOVECLIM. Finally, the low resolution can have an impact especially on the vegetation distribution which might change more on regional scales.

In Obata (2007) and Bozbiyik et al. (2011), the ocean globally takes up carbon as in Menviel et al. (2008). However the fresh water flux experiments differ, e.g. the duration is shorter. In Obata (2007) it results in a small change of carbon content in the ocean of around $+10 \mathrm{GtC}$. In this experiment, the AMOC slowly recovers and does not stay in an "off" mode. In Bozbiyik et al. (2011), the AMOC stays at a low level with an addition of $1 \mathrm{~Sv}$ in the North Atlantic. The 

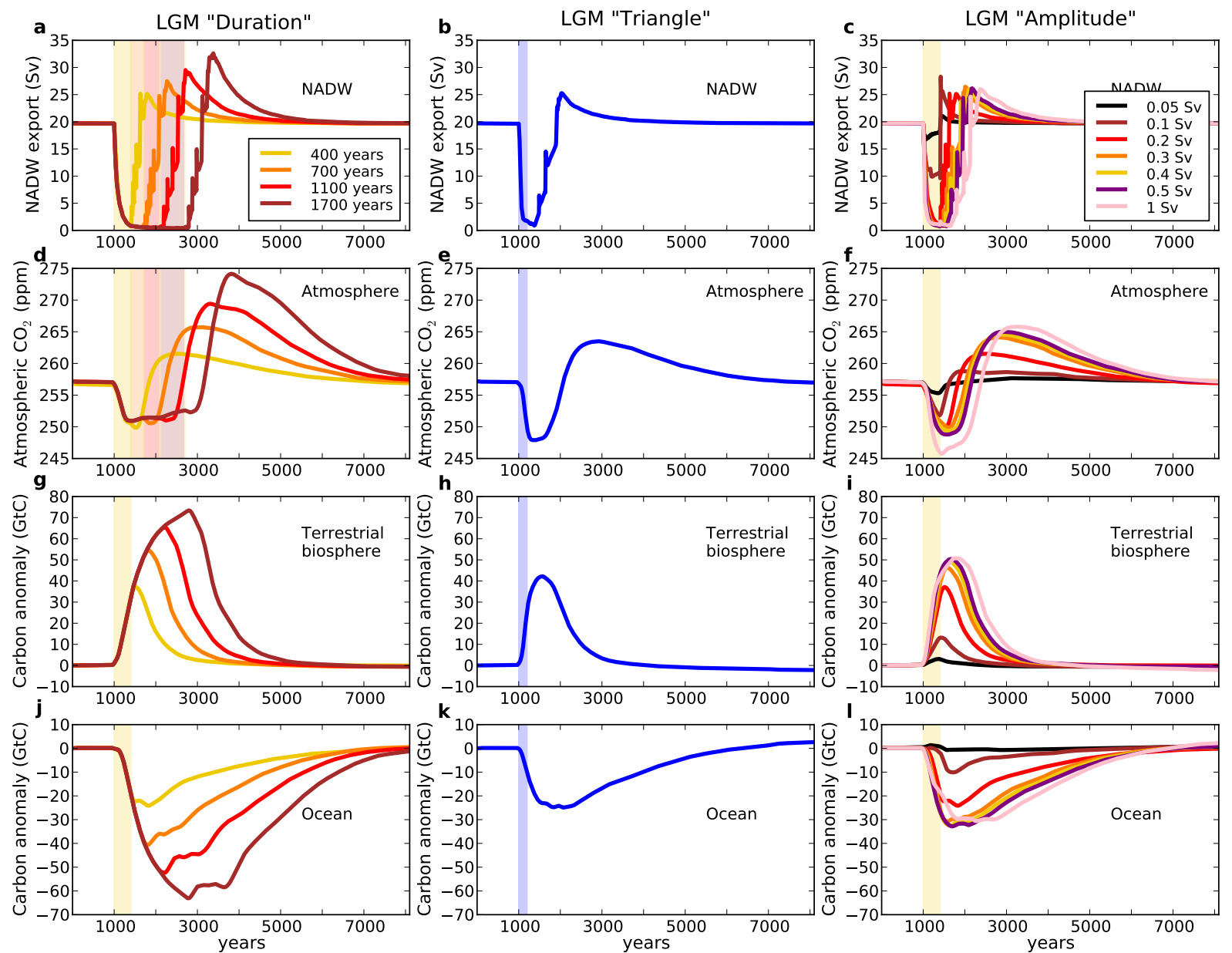

Fig. 10. Evolution of (a, b, c) NADW export (Sv) (maximum of the AMOC), (d, e, f) atmospheric $\mathrm{CO}_{2}(\mathrm{ppm}),(\mathbf{g}, \mathbf{h}$, i) carbon content anomaly in the terrestrial biosphere $(\mathrm{GtC})$ and $(\mathbf{j}, \mathbf{k}, \mathbf{l})$ carbon content anomaly in the ocean (GtC) during the simulations with the Last Glacial Maximum (LGM) background climate state. The fresh water flux is added into the North Atlantic and varies as described in Fig. 1 for the three types of experiments: (a, d, $\mathbf{g}, \mathbf{i})$ "Duration", (b, e, h, k) "Triangle" and (c, f, i, l) "Amplitude".
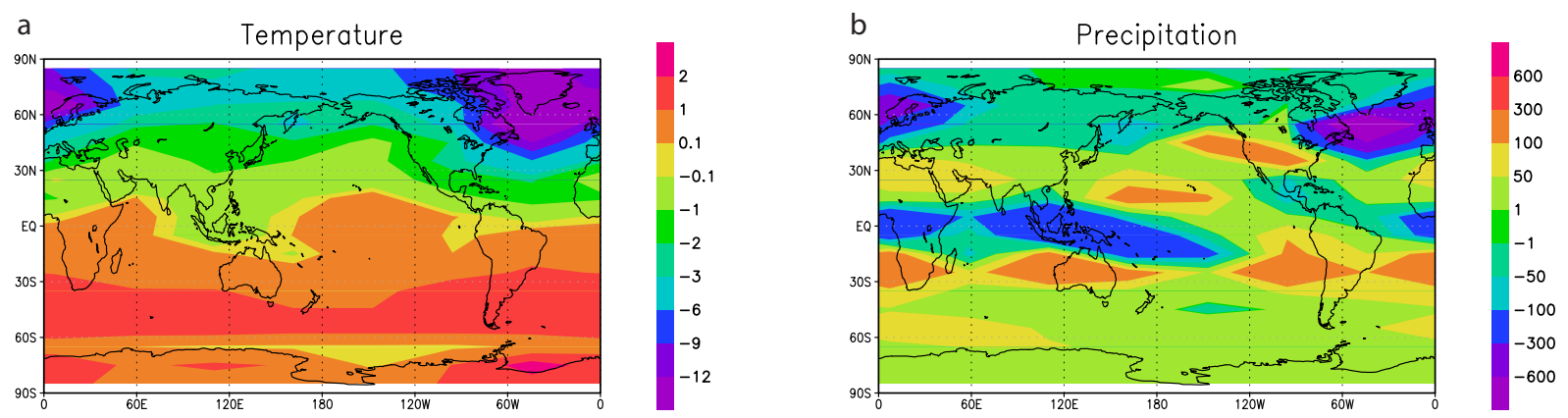

Fig. 11. Air temperature $\left({ }^{\circ} \mathrm{C}\right)$ and precipitation $\left(\mathrm{mm} \mathrm{yr}^{-1}\right)$ anomalies between the collapse state of the AMOC compared to the control state (years 1390-1400 minus years 990-1000). The simulation considered is during the LGM with a fresh water flux added into the North Atlantic of $0.5 \mathrm{~Sv}$ during $400 \mathrm{yr}$. 

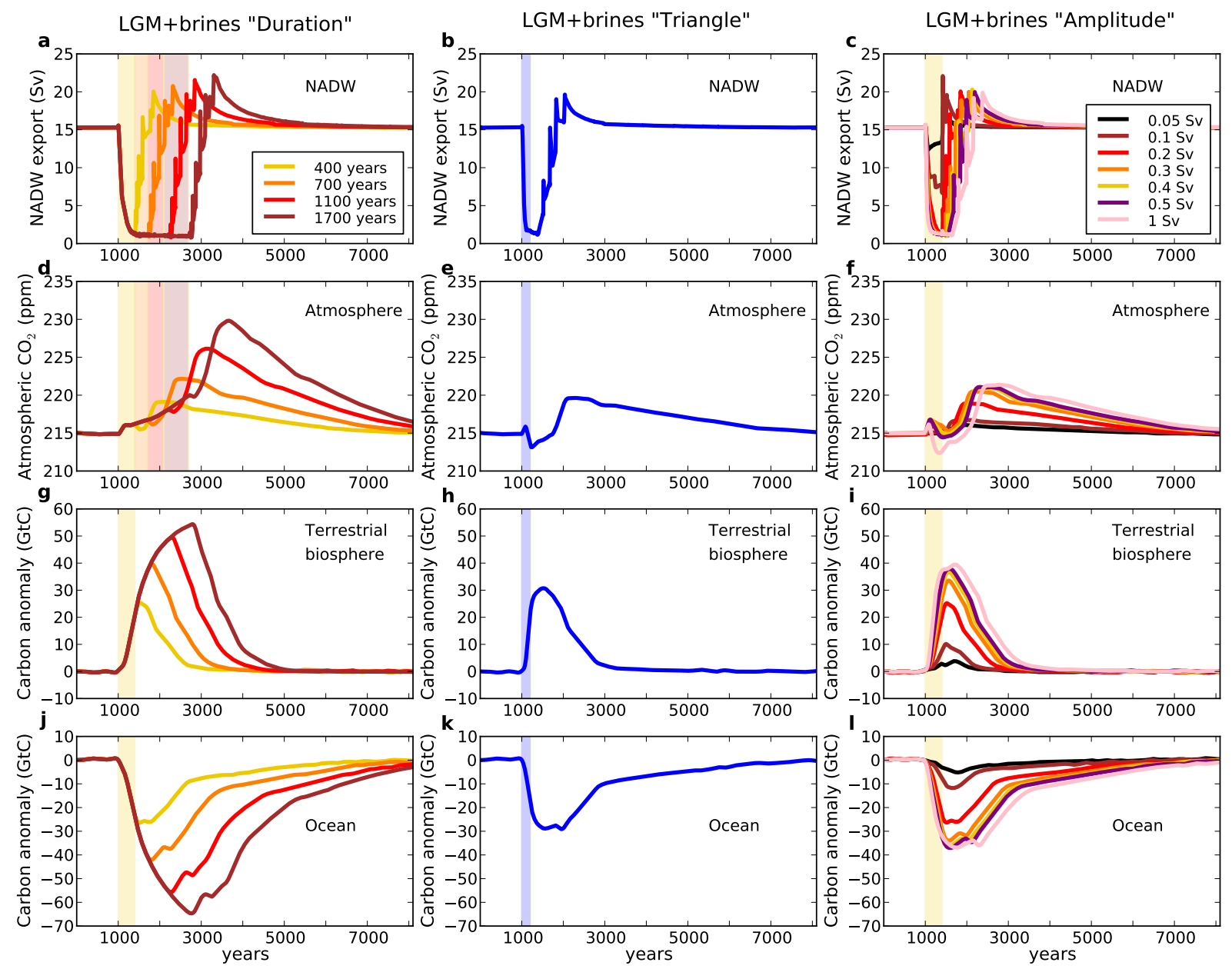

Fig. 12. Evolution of (a, b, c) NADW export (Sv) (maximum of the AMOC), (d, e, f) atmospheric $\mathrm{CO}_{2}(\mathrm{ppm}),(\mathbf{g}, \mathbf{h}$, i) carbon content anomaly in the terrestrial biosphere $(\mathrm{GtC})$ and $(\mathbf{j}, \mathbf{k}, \mathbf{l})$ carbon content anomaly in the ocean $(\mathrm{GtC})$ during the simulations with the Last Glacial Maximum background climate state and taking into account the sinking of brines (LGM + brines). The fresh water flux is added into the North Atlantic and varies as described in Fig. 1 for the three types of experiments: (a, d, g, i) "Duration", (b, e, h, k) "Triangle" and (c, f, i, l) "Amplitude".

effect on the carbon cycle is stronger with an uptake by the ocean of around $30 \mathrm{GtC}$. This uptake of carbon by the ocean is mostly due to the North Atlantic but also (with smaller amplitude) to most of the ocean in the Southern Hemisphere (except in the Atlantic). This is different in CLIMBER-2, in which the ocean in the Southern Hemisphere tends to contain less carbon because of the warmer waters.

In the previous experiments, the terrestrial biosphere was interactive. To test whether the ocean only reacts passively to the change of vegetation, we run an additional simulation with the vegetation fixed to its initial distribution. When the vegetation is fixed (Fig. 9), the ocean first takes up carbon by around $10 \mathrm{GtC}$, then looses carbon by around $50 \mathrm{GtC}$. In the simulation with interactive vegetation, the ocean loses carbon when the terrestrial biosphere takes up carbon and counteracts the atmospheric change of carbon content from the evolution of the vegetation. The simulation with fixed vege- tation displays a delay in the loss of carbon from the ocean by approximately $1500 \mathrm{yr}$ compared to the one with interactive vegetation. Indeed, the vegetation reacts quicker and the primary response of the ocean during the first $1500 \mathrm{yr}$ is to react to the decline of atmospheric $\mathrm{CO}_{2}$ due to the build-up of the terrestrial biosphere in the dynamic vegetation simulation. The ocean is almost passive. After around $1500 \mathrm{yr}$, the ocean actively looses carbon. If the vegetation is fixed, the ocean first acts as a source of carbon like the vegetation and then becomes a sink. The resulting evolution of atmospheric $\mathrm{CO}_{2}$ is not very different from the simulation with interactive vegetation.

It thus appears that applying different types of fresh water fluxes changing either their duration, amplitude or shape, cannot explain the differences obtained with different models. In CLIMBER-2, the type of fresh water flux modulates the change of $\mathrm{CO}_{2}$ : a longer or stronger fresh water flux will 

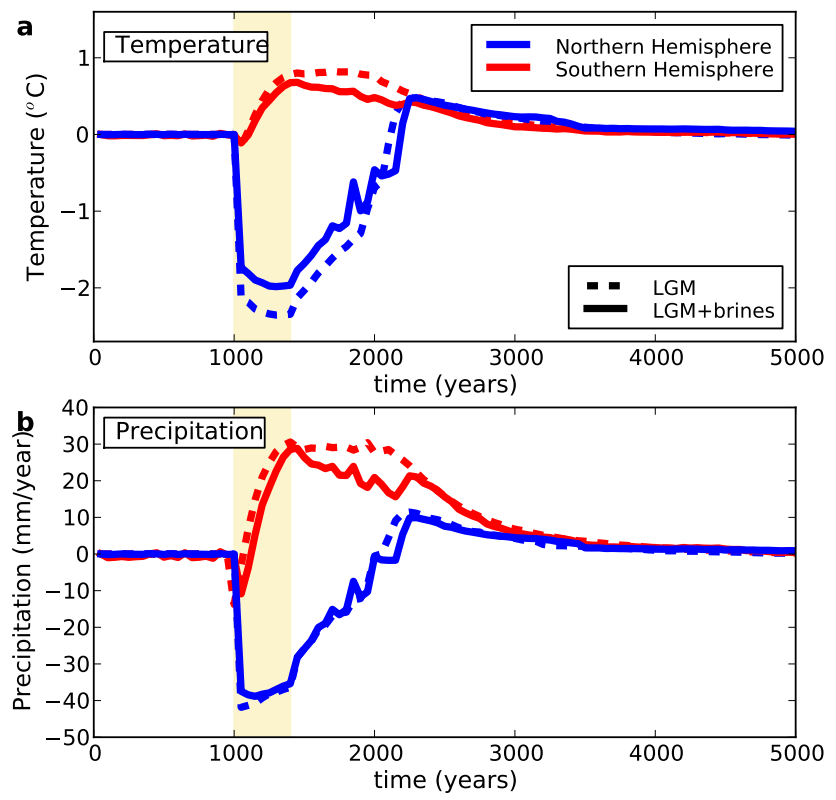

Fig. 13. Evolution of (a) air temperature $\left({ }^{\circ} \mathrm{C}\right)$ and (b) precipitation $\left(\mathrm{mm} \mathrm{yr}^{-1}\right)$ in the Northern (blue) and Southern (red) Hemispheres for the simulation with a fresh water flux added into the North Atlantic of $0.5 \mathrm{~Sv}$ during $400 \mathrm{yr}$. Two background climate states are considered: the Last Glacial Maximum (LGM, dashed lines) and the Last Glacial Maximum with the sinking of brines (LGM + brines, solid lines).

result in a larger $\mathrm{CO}_{2}$ increase. But it does not change the sign of the $\mathrm{CO}_{2}$ evolution as the terrestrial biosphere systematically releases carbon and the ocean takes up carbon. We now analyse the impact of the same fresh water fluxes during the glacial period to test whether the evolution of the carbon reservoirs changes, and how it compares to paleo data.

\subsection{Experiments with LGM background climate}

In the following, we explore the response of the model to fresh water fluxes in the context of the Last Glacial Maximum (LGM, approximately $21000 \mathrm{yr}$ ago). Two background conditions are considered: a standard glacial one (LGM) that can be compared to previous studies (Menviel et al., 2008; Schmittner and Galbraith, 2008) and a new one taking into account the sinking of brines rejected by sea ice formation around Antarctica (LGM + brines).

\subsubsection{Experiments with the standard LGM background climate}

We now analyze the impact of fresh water fluxes on the carbon cycle with a LGM background climate. As for the preindustrial simulations, the addition of fresh water slows down the AMOC (Fig. 10), resulting in a cooling in the North and warming in the South (Fig. 11a). The pattern of precipitation change is also similar to the PI one (Fig. 11b).
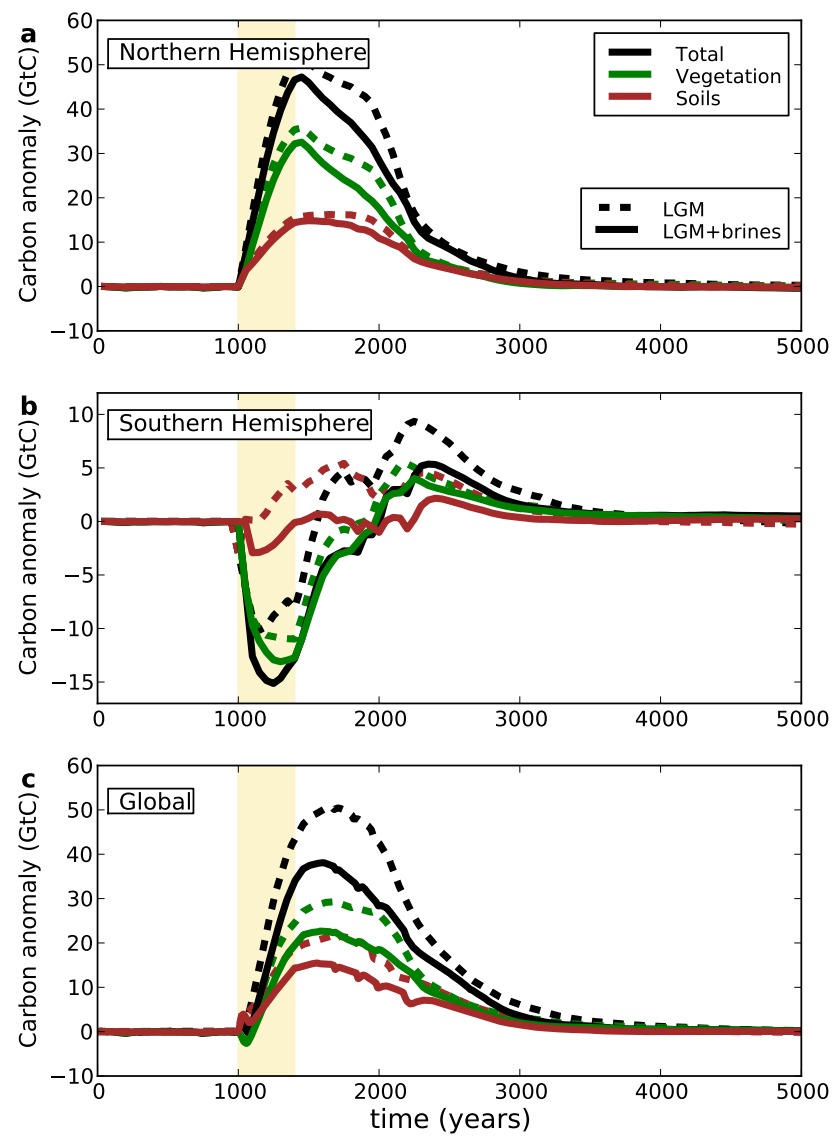

Fig. 14. Evolution of the carbon content anomaly in the terrestrial biosphere $(\mathrm{GtC})$ (a) in the Northern Hemisphere, (b) in the Southern Hemisphere and (c) total of the two hemispheres. The total carbon in the terrestrial biosphere (black) is decomposed in its two subreservoirs: the vegetation (green) and soils (brown). In the simulation the fresh water flux added into the North Atlantic has an amplitude of $0.5 \mathrm{~Sv}$ during $400 \mathrm{yr}$. Two background climate states are considered: the Last Glacial Maximum (LGM, dashed lines) and the Last Glacial Maximum with the sinking of brines (LGM + brines, solid lines).

With respect to the carbon cycle, the simulations with the LGM background climate present one major difference (Fig. 10) compared to the preindustrial climate results. The carbon cycle equilibrates at a different level than the initial one due to the AMOC evolution during the PI, while the final level is the same as the initial one with the LGM climate, because the AMOC stabilizes at its initial value. This stability under LGM conditions compared to PI conditions has been previously studied in CLIMBER-2 (Ganopolski and Rahmstorf, 2001). Other than that, the evolution is roughly similar because the pattern of climate change is close to the PI one, although the initial values are different due to the different background conditions. This confirms that the final equilibrium state that was found in the PI experiments is not relevant to the transient fluxes of carbon during the FWF perturbation. 
Consequently, the general evolution of $\mathrm{CO}_{2}$ is a relatively small decrease (less than $12 \mathrm{ppm}$ ), then a bigger increase (up to $25 \mathrm{ppm}$ ) and a reduction to the initial level.

Two ocean-atmosphere-vegetation models have already studied the carbon cycle response to a weakening of the AMOC during the LGM. In the LOVECLIM model (Menviel et al., 2008), it again results in an oceanic carbon uptake and loss of carbon from the terrestrial biosphere, but the result is slightly different. Because the ocean takes up carbon more rapidly, it results in a decrease of $\mathrm{CO}_{2}$ during the first $400 \mathrm{yr}$, then a small increase. On the other hand, the UVic model (Schmittner and Galbraith, 2008) gives opposite results: the ocean looses carbon while the terrestrial biosphere takes up carbon. It leads to $\mathrm{a}_{2}$ rise in the UVic model and a $\mathrm{CO}_{2}$ decline in LOVECLIM, then a return towards near initial conditions.

The CLIMBER-2 results are more similar to the UVic ones, with a loss of carbon from the ocean and an uptake from the terrestrial biosphere. The result is however slightly different, with first a small decrease of $\mathrm{CO}_{2}$. It then increases as in Schmittner and Galbraith (2008). The $\mathrm{CO}_{2}$ evolution depends on the tight interplay of ocean and terrestrial biosphere. Because the terrestrial biosphere reacts faster than the ocean, its response at the beginning of the weakening of the AMOC is important for the $\mathrm{CO}_{2}$ evolution.

As for the preindustrial state, the evolution of the carbon content in the ocean and terrestrial biosphere is the opposite in CLIMBER-2 and LOVECLIM; it is however similar in UVic and CLIMBER-2. Such discrepancies do not arise from the differences in the type of fresh water flux as they were similar in CLIMBER-2 and the other models. Hence they can come from the different AMOC change and the climatic responses of the models to this AMOC evolution.

In both UVic and CLIMBER-2, the AMOC stays in the "off mode" longer, which can result in a more important impact of the deeper part of the ocean. The soils can also play a greater role as their turnover time is longer than that of the vegetation. The change of climate can also be different in response to the AMOC shut down.

Changing the background climate can have an important effect on the evolution of the carbon cycle when fresh water is added, both because the initial state is different, so that the repartition of carbon in the reservoirs is different, and because the climate change is different. With CLIMBER-2, the pattern of the induced climate change for the glacial state is relatively similar to the one for the preindustrial state. Hence the sign of the change of carbon in the terrestrial biosphere and the ocean is the same, but the amplitudes differ. As the initial state plays an important role, we also explore the impact of fresh water flux on the evolution of the carbon cycle when the sinking of brines in the Southern Ocean is taken into account during the glacial period.

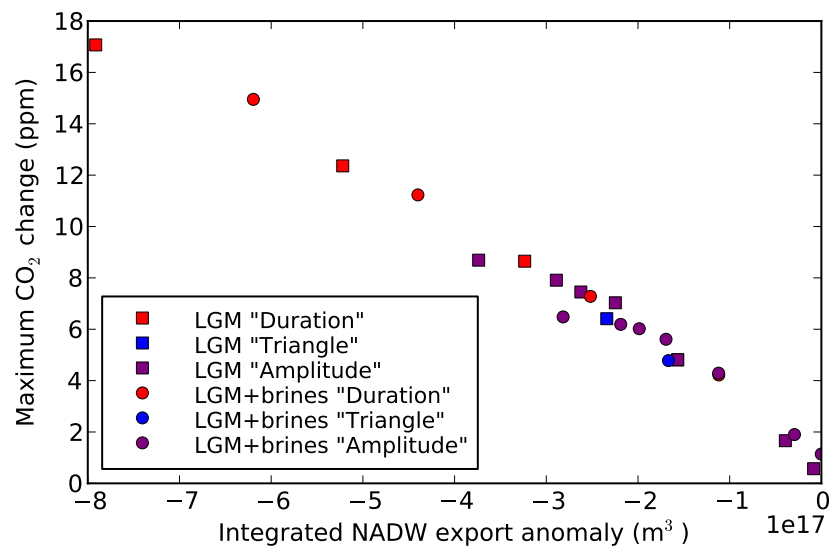

Fig. 15. Maximum of the $\mathrm{CO}_{2}$ change (as a difference from the initial value) (ppm) as a function of the integrated NADW export anomaly over time $\left(\mathrm{m}^{3}\right)$. The NADW anomaly is taken as the difference between the maximum value of the AMOC at a given time and the maximum value at the beginning of the simulation.

\subsubsection{Experiments with LGM background climate and brines}

In the previous experiments, the background climate was the LGM, but the simulated $\mathrm{CO}_{2}$ level was not coherent with the glacial $\mathrm{CO}_{2}$ level (similar to (Schmittner and Galbraith, 2008)) inferred from ice core data (around $190 \mathrm{ppm}$ during the LGM, between $190 \mathrm{ppm}$ and $220 \mathrm{ppm}$ from $-65000 \mathrm{yr}$ to the LGM, compared to approximately $257 \mathrm{ppm}$ in CLIMBER-2). Previous studies have shown that it is possible to simulate the glacial carbon cycle in better agreement with the data by including a brine mechanism (Bouttes et al., 2010, 2011). The rejection of salt during sea ice formation around Antarctica leads to a sinking of very saline and dense water to the deep ocean. It results in a more stratified deep ocean that contains more carbon. We use this LGM with brines climate background to explore the evolution of the carbon cycle when an additional FWF is put into the North Atlantic.

The addition of fresh water still leads to an uptake of carbon by the terrestrial biosphere and a release of carbon by the ocean. However the amplitude of the terrestrial biosphere increase is smaller, while the oceanic one is similar (Fig. 12). Hence, there is no more $\mathrm{CO}_{2}$ decrease at the beginning of the experiment: $\mathrm{CO}_{2}$ rises then declines.

What can explain these changes? The initial level of NADW export is lower in the LGM + brines simulations compared to the LGM ones ( $15 \mathrm{~Sv}$ compared to $20 \mathrm{~Sv}$ in the LGM experiments). When the fresh water is added, the resulting decrease of NADW export is smaller with the sinking of brines, and the induced climate change is slightly smaller (Fig. 13). Because the amplitude of the climate change is smaller, it leads to smaller changes of the carbon content in the terrestrial biosphere (Fig. 14). Indeed, the ultimate 

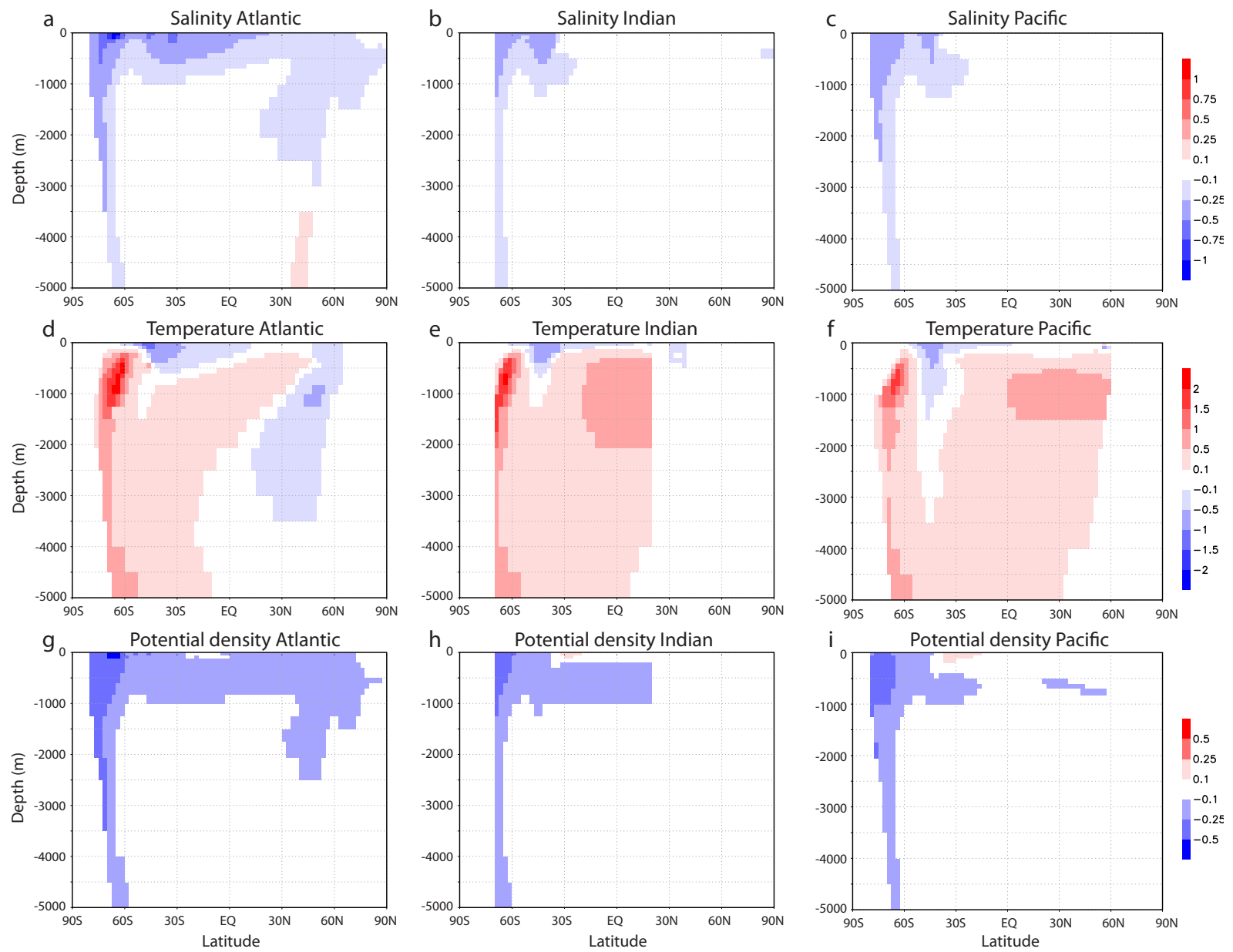

Fig. 16. Zonally averaged salinity $(\% \circ)$, temperature $\left({ }^{\circ} \mathrm{C}\right)$ and density $\left(\mathrm{kg} \mathrm{m}^{-3}\right)$ anomalies for the simulation during the Preindustrial with a fresh water flux added into the southern part of the Atlantic of $0.5 \mathrm{~Sv}$ during $400 \mathrm{yr}$ : (a, b, c) salinity; (d, e, f) temperature; (g, h, i) density. The anomalies refer to the difference between the collapse state of the AMOC compared to the control state (years 1390-1400 minus years 990-1000). The three basins are: (a, d, g) Atlantic, (b, e, h) Indian and (c, f, i) Pacific.

driver of the $\mathrm{CO}_{2}$ change appears to be both the timing and amplitude of the AMOC weakening. As shown on Fig. 15, the maximum $\mathrm{CO}_{2}$ increase depends on the integral of the AMOC below its initial value. It thus appears necessary to have a shutdown of the AMOC for a sufficient duration to obtain a $\mathrm{CO}_{2}$ rise similar to the data (around $15 \mathrm{ppm}$ ). In the model, this requires a substantial addition of fresh water ( $0.2 \mathrm{~Sv}$ during $1700 \mathrm{yr}$ ). It should be noted, however, that the amount of freshwater flux to be added in one model to shutdown the AMOC is very model dependent. The $\mathrm{CO}_{2}$ amplitude change during an AMOC shutdown thus gives an indication of the length of disruption of the AMOC. Or, more importantly, if we have a period of time in the past with disrupted $A M O C$ and measures of the $\mathrm{CO}_{2}$ concentration for the same period, we can derive an estimate of the rate of AMOC before the shutdown using the $\mathrm{CO}_{2}$ change as a measure for the rate.
It appears that the strength of the AMOC prior to the event plays a role because it impacts the amplitude of the climate change. The latter directly impacts the evolution of the terrestrial biosphere. In LOVECLIM, the AMOC initial level is very high compared to UVic and CLIMBER-2: $30 \mathrm{~Sv}$ compared to $20 \mathrm{~Sv}$ in CLIMBER-2 at LGM, $15 \mathrm{~Sv}$ for LGMb and only $13 \mathrm{~Sv}$ in UVic. The initial value of the AMOC could partly explain the differences in the amplitude of the vegetation response, but not the opposite sign between Menviel et al. (2008) and the others, which arises from the different climatic response obtained in the different models.

\subsection{FWF in the Southern Hemisphere: similar or different impacts?}

The possibility of fresh water fluxes in the Southern Ocean has also been suggested, for example to explain the onset of the Bølling-Allerød warm period (Weaver et al., 2003). 

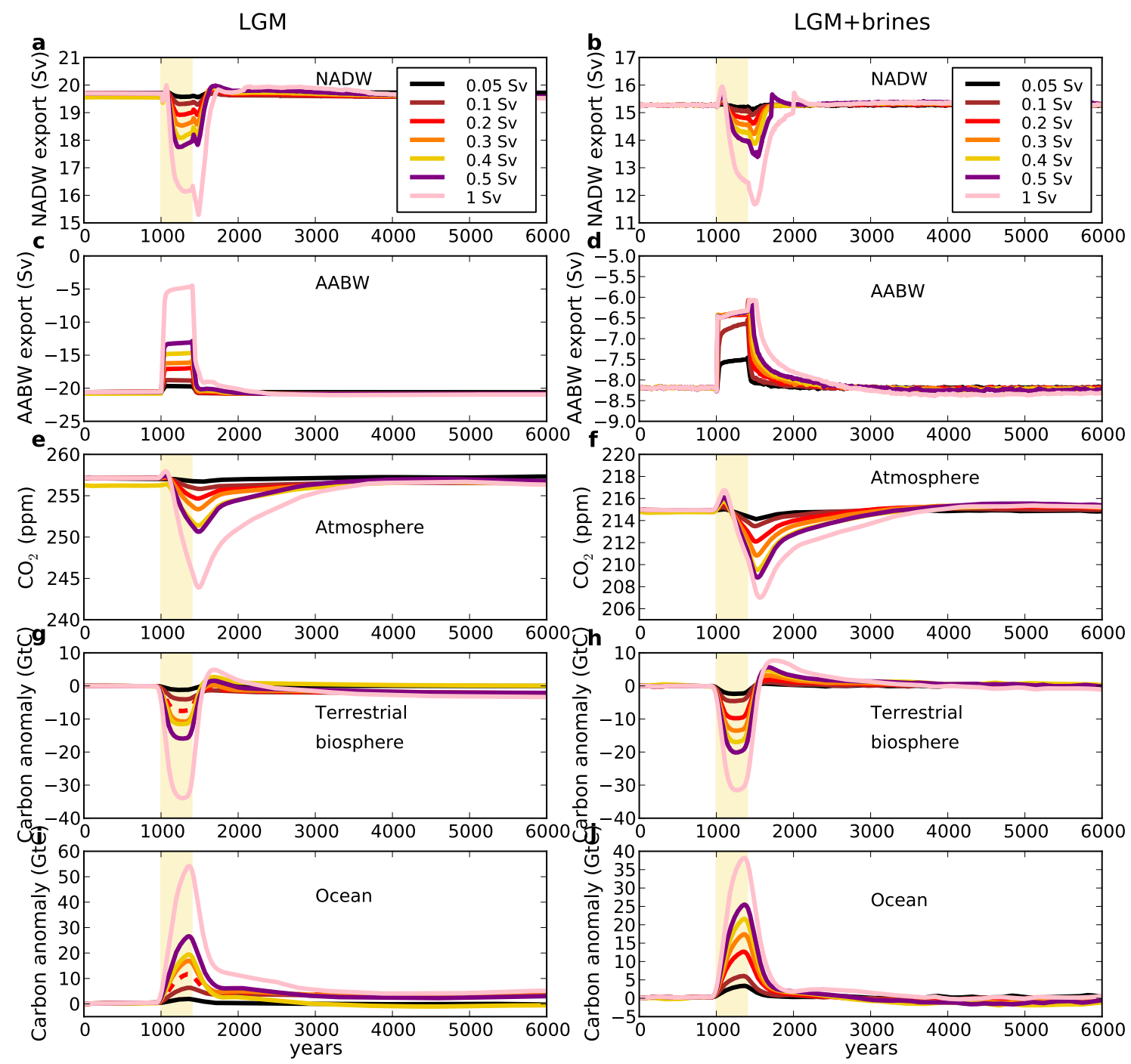

Fig. 17. Evolution of oceanic variables in response to the addition of fresh water into the southern part of the Atlantic following the "Amplitude" experiments (Fig. 1c). (a, b) NADW export (Sv) (maximum of the AMOC), (c, d) AABW export (Sv) (maximum of the overturning cell in the Southern Ocean, the sign indicates that the transport is from the South to the North), $(\mathbf{e}, \mathbf{f})$ atmospheric $\mathrm{CO}_{2}$ (ppm), $(\mathbf{g}, \mathbf{h})$ carbon content anomaly in the terrestrial biosphere $(\mathrm{GtC})$ and $(\mathbf{i}, \mathbf{j})$ carbon content anomaly in the ocean $(\mathrm{GtC})$. The simulations are performed with two background climate states: (a, c, e, g, i) during the Last Glacial Maximum (LGM) and (b, d, f, h, j) during the Last Glacial Maximum with the sinking of brines (LGM + brines).

The climatic impact of fresh water release in the Southern Ocean has been analysed in previous studies (Richardson et al., 2005; Stouffer et al., 2006; Swingedouw et al., 2008, 2009; Menviel et al., 2010). Adding fresh water in the Southern Ocean generally leads to a reduction of the ventilation of deep waters around Antarctica, a cooling in the surface Southern Ocean and a warming deeper in the ocean. However, the resulting impact on atmospheric $\mathrm{CO}_{2}$ is small in the LOVECLIM model (Menviel et al., 2010). To evaluate the impact of additional fresh water flux in CLIMBER-2, we run additional experiments. We perform the same set of experiments as the "Amplitude" ensemble (Fig. 1c), but we now add the fresh water into the southern part of the Atlantic. We consider two background climate states: the Last Glacial Maximum (LGM) and Last Glacial Maximum with the sinking of brines (LGM + brines).

Adding fresh water in the Southern Hemisphere decreases the salinity and the potential density locally (Fig. 16). It impacts mainly the Antarctic Bottom Water (AABW) export, whose intensity diminishes (Figs. 17c-d and 18), in agreement with previous studies (Richardson et al., 2005; Stouffer et al., 2006; Swingedouw et al., 2009; Menviel et al., 2010). The NADW export is also weakened (Figs. 17a-b and 18), but with a small amplitude (around $2 \mathrm{~Sv}$ for the 

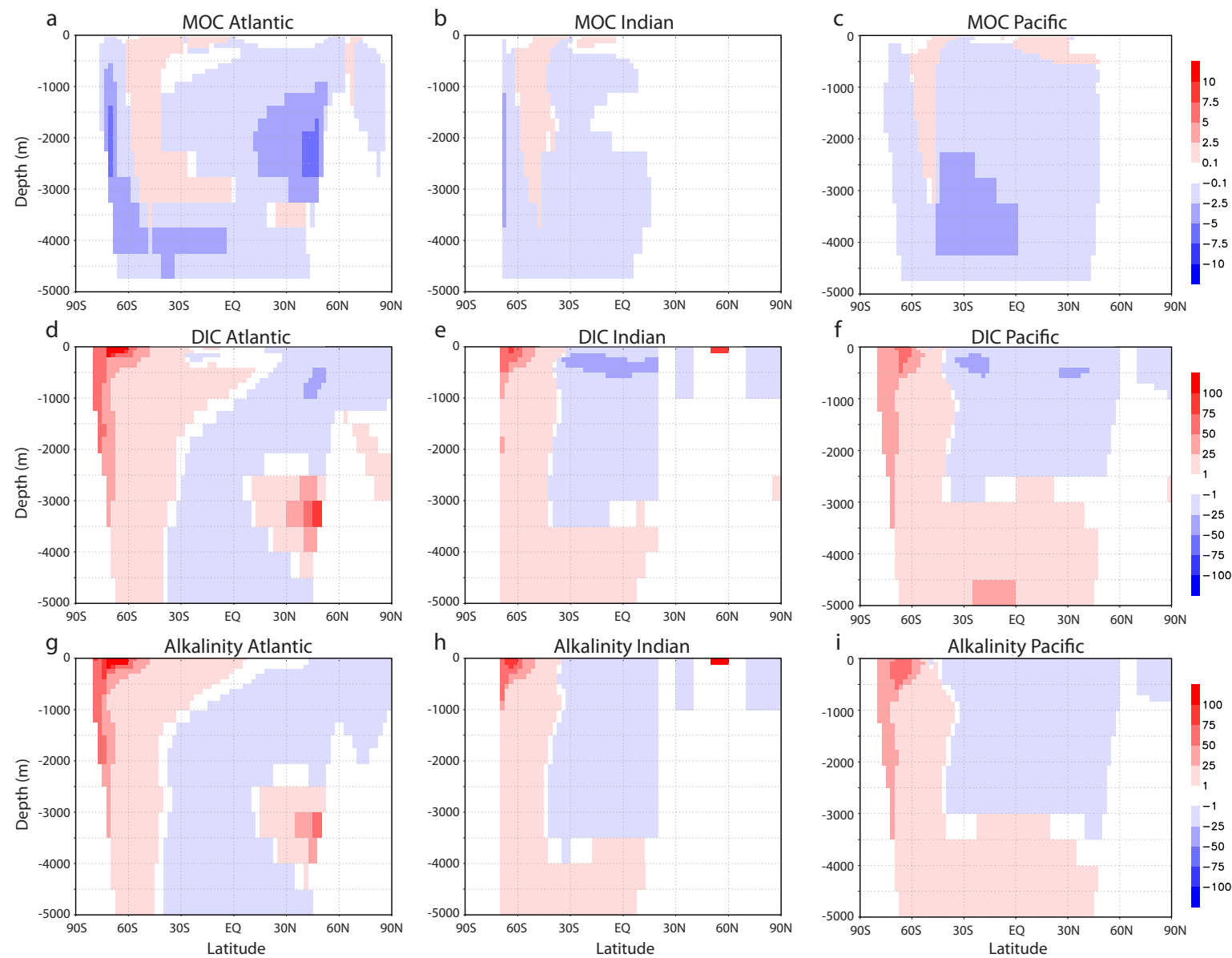

Fig. 18. Meridional overturning streamfunction (Sv), zonally averaged dissolved inorganic carbon and alkalinity ( $\left.\mu \mathrm{mol} \mathrm{kg}^{-1}\right)$ anomalies for the simulation during the Preindustrial with a fresh water flux added into the southern part of the Atlantic of 0.5 Sv during 400 yr: (a, b, c) inorganic carbon difference between the average of years 990-1000 and years 1390-1400; (d, e, f) alkalinity difference between the average of years 990-1000 and years 1390-1400. The three basins are: (a, d) Atlantic, (b, e) Indian and (c, f) Pacific.

$0.5 \mathrm{~Sv}$ experiment). As already analyzed in previous studies, the surface Southern Ocean cools while the subsurface water warms (Fig. 16).

The resulting $\mathrm{CO}_{2}$ evolution is very different from the one obtained with the FWF in the Northern Hemisphere, showing a decrease (with a maximum amplitude of around $13 \mathrm{ppm}$ ) then an increase (Fig. 17e and f). This is due to the ocean and terrestrial biosphere reservoirs, whose evolutions are the opposite as the ones with the additional FWF in the Northern Hemisphere (Fig. 17g-j). Indeed, air temperature and precipitation are now reduced in both hemispheres (Fig. 19), with greater amplitudes in the Southern Hemisphere. The colder and dryer conditions result in a decrease of carbon in the vegetation.

In the ocean, the temperature drop in the surface leads to a higher solubility for $\mathrm{CO}_{2}$. As neither NADW nor AABW formation is "off", the surface water, which contains more carbon, can be transported to the deep ocean, thus an ocean carbon uptake is observed. Indeed, the prevailing change of
DIC is an increase in the southern part of the three oceans (South of $40^{\circ} \mathrm{S}$ ) and in the deep Indian and Pacific ocean (Fig. 18). The distribution of the alkalinity change is similar to the DIC one, but its amplitude is slightly smaller and the change of DIC prevails.

Because the amplitude of the ocean change is more important than the vegetation change, the ocean evolution dominates and it results in a $\mathrm{CO}_{2}$ decrease. Hence adding fresh water in the Southern Hemisphere cannot explain the $\mathrm{CO}_{2}$ rise during Heinrich events. However, it could play a role during the deglaciation, as the data show a momentary stop in the $\mathrm{CO}_{2}$ increase during the Antarctic Cold Reversal (Monnin et al., 2001; Köhler et al., 2011). Besides its potential effect on $\mathrm{CO}_{2}$, the impact of additional fresh water in the Southern Hemisphere during deglaciation has recently been tested with success in a transient simulation of deglaciation (Menviel et al., 2011). 

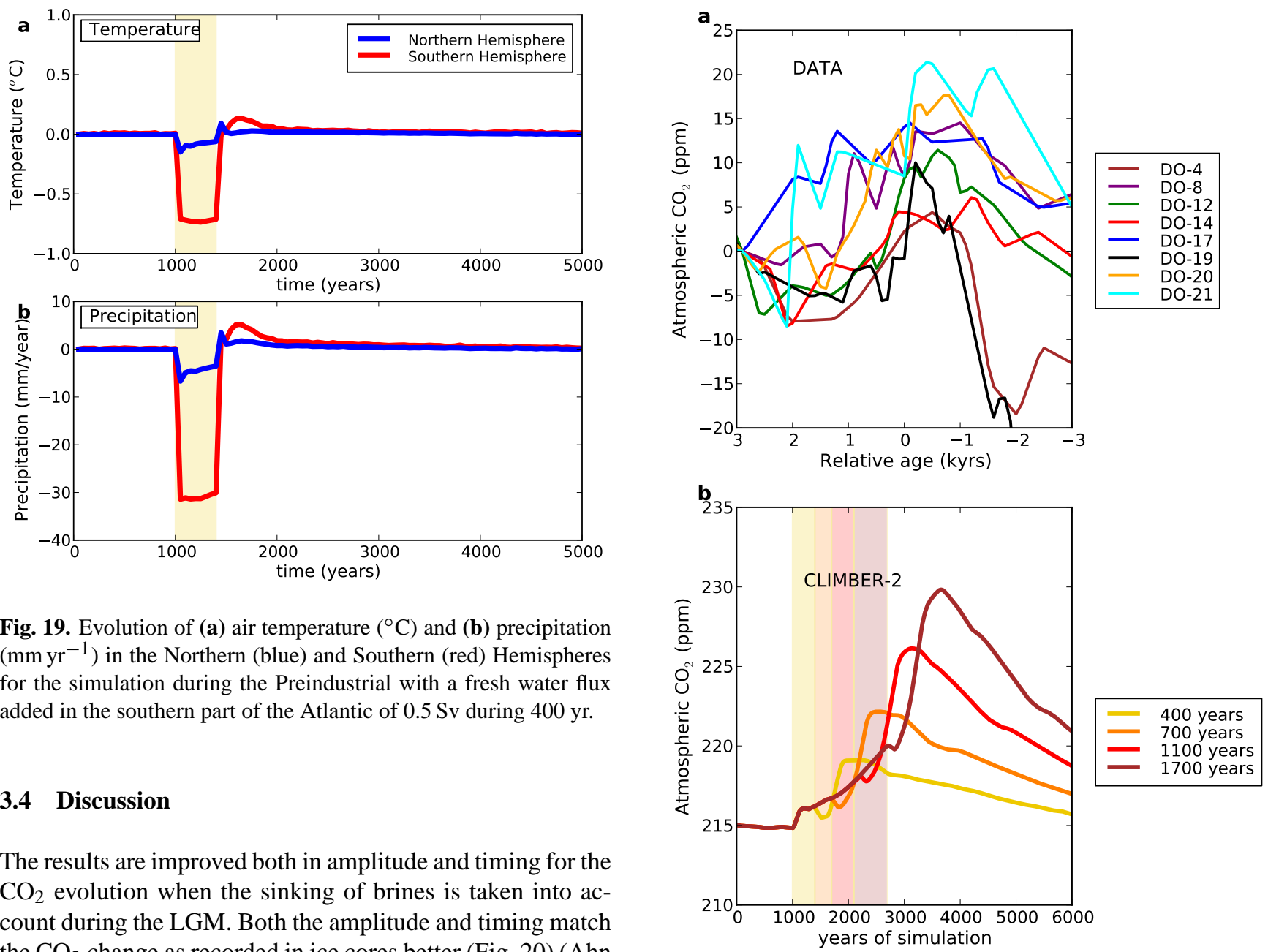

Fig. 19. Evolution of (a) air temperature $\left({ }^{\circ} \mathrm{C}\right)$ and (b) precipitation $\left(\mathrm{mm} \mathrm{yr}^{-1}\right)$ in the Northern (blue) and Southern (red) Hemispheres for the simulation during the Preindustrial with a fresh water flux added in the southern part of the Atlantic of $0.5 \mathrm{~Sv}$ during $400 \mathrm{yr}$.

\subsection{Discussion}

The results are improved both in amplitude and timing for the $\mathrm{CO}_{2}$ evolution when the sinking of brines is taken into account during the LGM. Both the amplitude and timing match the $\mathrm{CO}_{2}$ change as recorded in ice cores better (Fig. 20) (Ahn and Brook, 2008). This could be due to the initial state of NADW, whose strength is lower with the brines compared to the simulation without. With the sinking of brines and the induced stratification, carbon is stored in the abyssal glacial ocean (Bouttes et al., 2010, 2011). This different carbon cycle state could explain part of the change, as the ocean contains more carbon and can thus be more sensitive to changes in the AMOC. Such an impact of the sinking of brines on the state of the glacial ocean remains to be tested with 3dimensional models.

A slightly slower AMOC is in agreement with data indicating that the intensity of the AMOC during the LGM is comparable or lower than today, but not shut down nor accelerated (Lynch-Stieglitz et al., 2007; McManus et al., 2004). Furthermore, a more realistic representation of the brine mechanism would depend on climate, with the sinking of brines to the abyss being reduced when the Southern Ocean temperatures are rising. This additional feedback would likely amplify the carbon oceanic response and consequently the atmospheric $\mathrm{CO}_{2}$ rise.

Finally, the fresh water flux into the Southern Ocean leads to an opposite $\mathrm{CO}_{2}$ evolution marked by a decrease followed by an increase. Such an impact of fresh water fluxes from 


\section{Conclusions}

In conclusion, we have explored the impact of different fresh water fluxes in several climate background states with the CLIMBER-2 model. The duration, amplitude, and shape of the fresh water flux all modulate the evolution of the ocean circulation and the carbon cycle. The longer or greater the flux, the bigger the increase of atmospheric $\mathrm{CO}_{2}$ is. However, they cannot explain the differences obtained in different models, i.e. why in some models the ocean takes up carbon while the vegetation releases it and the opposite in other models. In CLIMBER-2 the AMOC takes time before it recovers, which can lead to a greater role of the deeper ocean. The different background states have an important impact on the carbon cycle, especially as the carbon inventories in the ocean, terrestrial biosphere and atmosphere are different. Taking into account the sinking of brines in the Southern Ocean in a glacial climate allows $\mathrm{CO}_{2}$ to start from a value which is closer to proxy data and gives a more similar evolution compared to the ice core records. The location of the fresh water flux has a strong impact on the evolution of the carbon cycle as it results in a very different climatic response. In CLIMBER-2 it leads to a decrease of $\mathrm{CO}_{2}$ contrary to the addition of fresh water in the Northern Hemisphere. Finally, as shown by previous studies, the response of the carbon cycle strongly depends on a close interplay between the ocean and vegetation responses. The results are very model dependent, both because of the response of the AMOC to the addition of fresh water and because of the climatic response to this fresh water flux. A better understanding of these differences will require an intercomparison of the impact of the addition of fresh water in carbon-climate models, using a well-defined common experimental setup.

Acknowledgements. We thank the editor, two anonymous reviewers, as well as Laurie Menviel and Axel Timmermann for constructive comments that helped improve the manuscript.

Edited by: H. Fischer

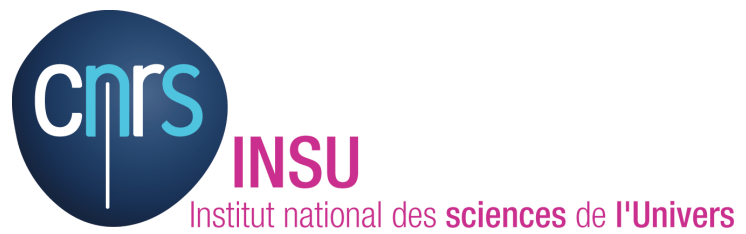

The publication of this article is financed by CNRS-INSU.

\section{References}

Ahn, J. and Brook, E. J.: Atmospheric $\mathrm{CO}_{2}$ and Climate on Millennial Time Scales During the Last Glacial Period, Science, 322, 83-85, 2008.

Alvarez-Solas, J., Charbit, S., Ritz, C., Paillard, D., Ramstein, G., and Dumas, C.: Links between ocean temperature and ice- berg discharge during Heinrich events, Nat. Geosci., 3, 122-126, doi:10.1038/ngeo752, 2010.

Barker, S., Diz, P., Vautravers, M. J., Pike, J., Knorr, G., Hall, I. R., and Broecker, W. S.: Interhemispheric Atlantic seesaw response during the last deglaciation, Nature, 457, 1097-1102, doi:10.1038/nature07770, 2009.

Berger, A. L.: Long-term variations of daily insolation and Quaternary climatic changes, J. Atmos. Sci., 35, 2362-2368, 1978.

Bond, G., Broecker, W., Johnsen, S., McManus, J., Labeyrie, L., Jouzel, J., and Bonani, G.: Correlations between climate records from North Atlantic sediments and Greenland ice, Nature, 365, 143-147, doi:10.1038/365143a0, 1993.

Bouttes, N., Paillard, D., and Roche, D. M.: Impact of brineinduced stratification on the glacial carbon cycle, Clim. Past, 6, 575-589, doi:10.5194/cp-6-575-2010, 2010.

Bouttes, N., Paillard, D., Roche, D. M., Brovkin, V., and Bopp, L.: Last Glacial Maximum $\mathrm{CO}_{2}$ and $\delta^{13} \mathrm{C}$ successfully reconciled, Geophys. Res. Lett., 38, L02705, doi:10.1029/2010GL044499, 2011.

Bozbiyik, A., Steinacher, M., Joos, F., Stocker, T. F., and Menviel, L.: Fingerprints of changes in the terrestrial carbon cycle in response to large reorganizations in ocean circulation, Clim. Past, 7, 319-338, doi:10.5194/cp-7-319-2011, 2011.

Brovkin, V., Ganopolski, A., and Svirezhev, Y.: A continuous climate-vegetation classification for use in climate-biosphere studies, Ecol. Modell., 101, 251-261, 1997.

Brovkin, V., Hofmann, M., Bendtsen, J., and Ganopolski, A.: Ocean biology could control atmospheric $\delta^{13} \mathrm{C}$ during glacial-interglacial cycle, Geochem. Geophy. Geosys., 3, 1027, doi:10.1029/2001GC000270, 2002.

Brovkin, V., Ganopolski, A., Archer, D., and Rahmstorf, S.: Lowering of glacial atmospheric $\mathrm{CO}_{2}$ in response to changes in oceanic circulation and marine biogeochemistry, Paleoceanography, 22, PA4202, doi:10.1029/2006PA001380, 2007.

Clark, P. U., Dyke, A. S., Shakun, J. D., Carlson, A. E., Clark, J., Wohlfarth, B., Mitrovica, J. X., Hostetler, S. W., and McCabe, A. M.: The Last Glacial Maximum, Science, 325, 710714, doi:10.1126/science.1172873, 2009.

Clement, A. C. and Peterson, L. C.: Mechanisms of abrupt climate change of the last glacial period, Rev. Geophys., 46, RG4002, doi:10.1029/2006RG000204, 2008.

Crowley, T. J.: North Atlantic Deep Water cools the southern hemisphere, Paleoceanography, 7, 489-497, doi:10.1029/92PA01058, 1992.

EPICA community members: One-to-one coupling of glacial climate variability in Greenland and Antarctica, Nature, 444, 195198, doi:10.1038/nature05301, 2006.

Ganopolski, A. and Rahmstorf, S.: Rapid changes of glacial climate simulated in a coupled climate model, Nature, 409, 153$158,2001$.

Ganopolski, A., Petoukhov, V., Rahmstorf, S., Brovkin, V., Claussen, M., Eliseev, A., and Kubatzki, C.: CLIMBER-2: A climate system model of intermediate complexity, part II: Model sensitivity, Clim. Dynam., 17, 735-751, 2001.

Heinrich, H.: Origin and consequences of cyclic ice rafting in the Northeast Atlantic Ocean during the past 13,000 years, Quaternary Res., 29, 142-152, 1988.

Köhler, P., Joos, F., Gerber, S., and Knutti, R.: Simulated changes in vegetation distribution, land carbon storage, and atmospheric 
$\mathrm{CO}_{2}$ in response to a collapse of the North Atlantic thermohaline circulation, Clim. Dynam., 25, 689-708, doi:10.1007/s00382005-0058-8, 2005.

Köhler, P., Knorr, G., Buiron, D., Lourantou, A., and Chappellaz, J.: Abrupt rise in atmospheric $\mathrm{CO}_{2}$ at the onset of the Bølling/Allerød: in-situ ice core data versus true atmospheric signals, Clim. Past, 7, 473-486, doi:10.5194/cp-7-473-2011, 2011.

Lynch-Stieglitz, J., Adkins, J. F., Curry, W. B., Dokken, T., Hall, I. R., Herguera, J. C., Hirschi, J. J.-M., Ivanova, E. V., Kissel, C., Marchal, O., Marchitto, T. M., McCave, I. N., McManus, J. F., Mulitza, S., Ninnemann, U., Peeters, F., Yu, E.-F., and Zahn, R.: Atlantic Meridional Overturning Circulation During the Last Glacial Maximum, Science, 316, 66-69, doi:10.1126/science.1137127, 2007.

Mackintosh, A., Golledge, N., Domack, E., Dunbar, R., Leventer, A., White, D., Pollard, D., DeConto, R., Fink, D., Zwartz, D., Gore, D., and Lavoie, C.: Retreat of the East Antarctic ice sheet during the last glacial termination, Nat. Geosci., 4, 195202, doi:10.1038/ngeo1061, 2011.

Marchal, O., Stocker, T. F., and Joos, F.: Impact of oceanic reorganizations on the ocean carbon cycle and atmospheric carbon dioxide content, Paleoceanography, 13, 225-244, 1998.

McManus, J. F., Francois, R., Gherardi, J.-M., Keigwin, L. D., and Brown-Leger, S.: Collapse and rapid resumption of Atlantic meridional circulation linked to deglacial climate, Nature, 428, 834-837, doi:10.1038/nature02494, 2004.

Menviel, L., Timmermann, A., Mouchet, A., and Timm, O.: Meridional reorganizations of marine and terrestrial productivity during Heinrich events, Paleoceanography, 23, PA1203, doi:10.1029/2007PA001445, 2008.

Menviel, L., Timmermann, A., Timm, O. E., and Mouchet, A.: Climate and biogeochemical response to a rapid melting of the West Antarctic Ice Sheet during interglacials and implications for future climate, Paleoceanography, 25, PA4231, doi:10.1029/2009PA001892, 2010.

Menviel, L., Timmermann, A., Timm, O. E., and Mouchet, A.: Deconstructing the Last Glacial termination: the role of millennial and orbital-scale forcings, Quaternary Sci. Rev., 30), 1155-1172, 2011.

Monnin, E., Indermühle, A., Daellenbach, A., Flueckiger, J., Stauffer, B., Stocker, T. F., Raynaud, D., and Barnola, J.-M.: Atmospheric $\mathrm{CO}_{2}$ concentrations over the Last Glacial Termination, Science, 291, 112-114, 2001.

Obata, A.: Climate-Carbon Cycle Model Response to Freshwater Discharge into the North Atlantic, J. Climate, 20, 5962-5976, doi:10.1175/2007JCLI1808.1, 2007.

Peltier, W. R.: Global glacial isostasy and the surface of the ice-age Earth: The ICE-5G (VM2) Model and GRACE, Annu. Rev. Earth Planet. Sci., 32, 111-49, doi:10.1146/annurev.earth.32.082503.144359, 2004.
Petoukhov, V., Ganopolski, A., Eliseev, A., Kubatzki, C., and Rahmstorf, S.: CLIMBER-2: A climate system model of intermediate complexity, part I: Model description and performance for present climate, Clim. Dynam., 16, 1-17, 2000.

Rahmstorf, S.: Bifurcations of the Atlantic thermohaline circulation in response to changes in the hydrological cycle, Nature, 378, 145-149, doi:10.1038/378145a0, 1995.

Richardson, G., Wadley, M. R., Heywood, K. J., Stevens, D. P., and Banks, H. T.: Short-term climate response to a freshwater pulse in the Southern Ocean, Geophys. Res. Lett., 32, L03702, doi:10.1029/2004GL021586, 2005.

Ruddiman, W.: Late Quaternary deposition of ice-rafted sand in the sub-polar North Atlantic (lat $40^{\circ}$ to $65^{\circ}$ ), Geol. Soc. Am. Bull., 88, 1813-1821, 1977.

Schmittner, A. and Galbraith, E. D.: Glacial greenhouse-gas fluctuations controlled by ocean circulation changes, Nature, 456, 373-376, doi:10.1038/nature07531, 2008.

Stocker, T. F.: Climate change - the seesaw effect, Science, 282, 61-62, 1998.

Stocker, T. F. and Wright, D.: Rapid transitions of the ocean's deep circulation induced by changes in the surface water fluxes, Nature, 351, 729-732, 1991.

Stouffer, R. J., Yin, J., Gregory, J. M., Dixon, K. W., Spelman, M. J., Hurlin, W., Weaver, A. J., Eby, M., Flato, G. M., Hasumi, H., Hu, A., Jungclaus, J. H., Kamenkovich, I. V., Levermann, A., Montoya, M., Murakami, S., Nawrath, S., Oka, A., Peltier, W. R., Robitaille, D. Y., Sokolov, A., Vettoretti, G., and Weber, S. L.: Investigating the Causes of the Response of the Thermohaline Circulation to Past and Future Climate Changes, J. Climate, 19, 1365-1387, doi:10.1175/JCLI3689.1, 2006.

Swingedouw, D., Fichefet, T., Huybrechts, P., Goosse, H., Driesschaert, E., and Loutre, M.-F.: Antarctic ice-sheet melting provides negative feedbacks on future climate warming, Geophys. Res. Lett., 35, L17705, doi:10.1029/2008GL034410, 2008.

Swingedouw, D., Fichefet, T., Goosse, H., and Loutre, M. F.: Impact of transient freshwater releases in the Southern Ocean on the AMOC and climate, Clim. Dynam., 33, 365-381, doi:10.1007/s00382-008-0496-1, 2009.

Waelbroeck, C., Labeyrie, L., Michel, E., Duplessy, J. C., McManus, J. F., Lambeck, K., Balbon, E., and Labracherie, M.: Sea-level and deep water temperature changes derived from benthic foraminifera isotopic records, Quaternary Sci. Rev., 21, 295305, doi:10.1016/S0277-3791(01)00101-9, 2002.

Weaver, A. J., Saenko, O. A., Clark, P. U., and Mitrovica, J. X.: Meltwater Pulse 1A from Antarctica as a Trigger of the Bølling-Allerød Warm Interval, Science, 299, 1709-1713, doi:10.1126/science.1081002, 2003. 